\title{
THE ADAPTATION OF DUNES TO CHANGES IN RIVER FLOW
}

\author{
Reesink A.J.H..$^{(1,2,3,4)}$, Parsons D.R. ${ }^{(1)}$, Ashworth P.J. ${ }^{(2)}$, Best J.L. ${ }^{(3,5)}$, Hardy R.J. ${ }^{(6)}$, Murphy B.J. ${ }^{(1)}$, \\ $M^{c}$ Lelland, S.J. ${ }^{(1)}$, Unsworth C. ${ }^{(7)}$ \\ ${ }^{1}$ School of Environment and Earth Science (Geography), University of Hull, Hull, HU6 7RX, UK \\ ${ }^{2}$ Division of Geography and Geology, School of Environment and Technology, University of Brighton, \\ Brighton, Sussex, BN2 4GJ, UK \\ ${ }^{3}$ Department of Geology, University of Illinois at Urbana-Champaign, 1301 W. Green St., Urbana, IL, \\ 61801, USA \\ ${ }^{4}$ now at: Lancing College, Lancing, BN15 ORW, UK. Email: ajhr@lancing.org.uk \\ ${ }^{5}$ Departments of Geography and GIS, Mechanical Science and Engineering and Ven Te Chow \\ Hydrosystems Laboratory, University of Illinois at Urbana-Champaign, 1301 W. Green St., Urbana, IL, \\ 61801, USA, \\ ${ }^{6}$ Department of Geography, Durham University, Durham, DH1 3LE, UK \\ ${ }^{7}$ Department of Geography, University of Exeter, Exeter, EX4 4RJ, UK
}

Keywords: dunes; floods, hysteresis; bedforms; ripples; bedform superimposition; sediment transport

\section{ABSTRACT}

The dunes that cover the beds of most alluvial channels change in size and shape over time and in space, which in turn affects the flow and sediment-transport dynamics of the river. However, both the precise mechanisms of such adaptation of dunes, and the hydraulic variables that control these processes, remain inadequately understood. This paper provides an overview of the processes involved in the maintenance and adaptation of dunes, provides new tools for the analysis of dune dynamics, and applies these to a series of bespoke experiments.

Dunes that grow compete for space, and dunes that decay need to shed excess sediment. Therefore, dune adaptation necessarily involves the redistribution of sediment over and among dunes. The details of sediment redistribution are not captured by mean geometric parameters such as dune height and wavelength. Therefore, new analyses of dune kinematics, bed-elevation distributions, and dune deformation are presented herein that aid the identification and analysis of dune dynamics.

Dune adaptation is often described as a morphological response to changes in water depth at a rate that depends on sediment mobility, which itself is a product of flow depth and velocity. However, depth and velocity are out-of-phase during the passage of flood waves, and they vary spatially across rivers from the thalweg to bar tops, and downstream along the river profile. In order to improve our understanding of the hydraulic controls on dune morphology and kinematics, a series of experiments was performed to investigate the response of dunes in fully-mobile sand $\left(D_{50}=240 \mu \mathrm{m}\right)$ to changes in flow depth and velocity.

The experimental results illustrate that water depth and flow velocity have separate effects on the processes that control dune adaptation, and that the crests and troughs of dunes do not respond simultaneously to changes in flow. Trough scour increases with flow velocity, but superelevation of the dune crests appear to show only a weak relation with flow depth. Flattening-out of dune crests is related to decreasing depth and increasing flow velocity. Bedform superimposition, a key feature of bedform kinematics, was associated with increased flow depth, but was also systematically associated with local increases in the crest-to-crest distance following the dissipation of an upstream 
dune. Thus, local flow-form interactions have a significant effect on the manner in which sediment is redistributed over and among dunes. The splitting of dunes decreased in the downstream direction along the length of the flume, illustrating that the dunes continue to interact even after dune height has stabilised. Other processes, such as differential migration and dune merging, are ubiquitous during all flow conditions. These varied responses support the notion that the processes of dune adaptation vary over time and in space.

Analysis of dune deformation through examination of the residuals of cross-correlations between successive dune profiles illustrates that local sources and sinks of sediment exist within mobile dune fields. These findings highlight that dune adaptation to changes in flow is a dynamic response involving multiple interconnected dunes. The redistribution of sediment that is required for dunes to change shape and adapt to new conditions is expected to be an important cause of variability in sediment transport. These detailed analyses and findings provide a foundation for further study of dune dynamics in different environments on Earth as well as other planetary bodies.

\section{INTRODUCTION}

Dunes are the most prominent and dynamic bedforms in alluvial channels. Dune growth and decay affect flood height, flood-wave shape, and flood duration because dunes are a first order control on the form roughness and resistance of river beds (Simons and Richardson 1966; Van Rijn, 1984; 1993; Julien et al., 2002; Warmink et al., 2013). Coherent flow structures generated by dunes dictate the vertical exchange of momentum and sediment in the flow, which affects the dissipation of energy within the river as well as sediment budgets and bank erosion (Bennett and Best, 1995; Best, $2005 a, b)$. Dune growth during flood events can even affect infrastructure, such as bridge foundations and tunnels below the river bed (Amsler and García, 1997). Moreover, dune dynamics affect sediment transport dynamics (Kleinhans et al., 2007; Frings and Kleinhans, 2008), the development of cross-strata (Kleinhans, 2004, Reesink and Bridge, 2007, 2009, 2011), the preservation of sedimentary structures (Paola and Borgman, 1991; Leclair and Bridge, 2001; Jerolmack and Mohrig, 2005; Reesink et al., 2015), and the vertical and along-stream sediment grading of bed sediment that affects the concavity of the river profile (Hoey and Ferguson, 1994; Blom et al., 2003, 2006). Thus, the dynamic development of dunes needs to be understood to explain morphodynamic behaviour of river beds at a wide range of scales.

Dune development is controlled by the 'morphodynamic' feedback between the flow, sediment transport, and dune forms (e.g. Leeder, 1983; Best, 1993, 1996; Bridge, 1993; Carling et al., 2000; Church and Ferguson, 2015). Whereas significant advances have been made recently in quantification of flow over dunes through detailed measurements (Nelson et al., 1993; Bennett and Best, 1995; Best et al., 2010; Unsworth et al., in press.) and numerical models (e.g. Omidyeganeh and Piomelli, 2011, 2013a,b; Naqshband et al., 2014a; Schmeeckle, 2014, 2015), comparatively little is known about the processes of erosion and deposition that control how and why dunes change their shape as they migrate. The first objective of this study is therefore to investigate experimentally how dune geometries respond to changes in flow for a range of shallow, unidirectional flow conditions.

Dunes continuously deform as they migrate, even in conditions where statistical descriptors of the dune population have converged and the reach-averaged bed shear stress is constant (McElroy and Mohrig, 2009). In addition to such steady-state deformation, dunes also adapt to changes in flow. The adaptation of dunes is a response to both temporal changes in flow during floods (unsteady flow; e.g. Allen, 1973, 1974, 1982; Julien and Klaassen, 1995; Wilbers and Ten Brinke, 2003) and to spatial changes in flow related to channel form (non-uniform flow; e.g. Jackson, 1975, 1976; Nittrouer et al, 2008; Reesink et al., 2015). The distinction between deformation (not specific to 
disequilibrium) and adaptation (a consequence of disequilibrium conditions) is maintained herein. The physical processes that control the deformation and adaptation of dunes are not necessarily different, but will vary in magnitude and frequency (Kleinhans et al., 2007; McElroy and Mohrig, 2009; Martin and Jerolmack, 2013). Precisely how the magnitude of these processes is linked to their hydraulic controls is at present not adequately constrained. The second objective of this study is therefore to investigate how the processes that control the development of dune shape vary in response to changes in depth-averaged flow parameters, such as flow depth and velocity.

Recent advances in bathymetric survey techniques illustrate that dune geometries and dynamics vary greatly across bars and channels (Parsons et al., 2005; Nittrouer et al., 2008; Claude et al., 2012; Rodrigues et al., 2015; Almeida et al., 2016), and even at close proximity within a single, stabilised river (Kleinhans et al., 2007; Frings and Kleinhans, 2008). In spite of such variation, dunes in river channels are often assumed to follow the same predictive models (e.g. Giri and Shimizu, 2006; Paarlberg et al., 2009; Nabi et al., 2013, 2015). Dunes are also often compared between different environments, such as rivers, estuaries, shallow seas, deserts (Kocurek and Ewing, 2005), and even other planets (e.g. Cutts and Smith, 1973; Diniega et al., 2016) and asteroids (Thomas et al., 2015). However, no comprehensive conceptual framework is currently available to identify and interpret differences in the development and 'behaviour' of dunes in these contrasting environments. There is a distinct possibility that different processes may lead to similar sand bed morphologies (equifinality) and that multiple processes are involved in bedform maintenance and evolution at any one time (multiplicity; Schumm, 1998; Kleinhans et al., 2017). The final objective of the present paper is therefore to test new analytical tools for analysis of the development of dune shape.

To begin to investigate the dynamic changes in dune geometry (first objective) and the processes that cause them (second objective) by means of a number of new analytical tools (third objective), a series of physical experiments are presented herein that aim to monitor the response of mobile sand dunes in shallow, unidirectional flows to changes in flow depth (depth 0.17-0.25 m) and velocity (0.46-0.66 $\left.\mathrm{m} \mathrm{s}^{-1}\right)$. The dynamics observed in the experiments are unlikely to represent the dynamics of dunes in deep water (depth-independent behaviour, c.f. Flemming and Bartholomä, 2012), multidirectional flows, or air. However, the theory and methods of the present study provide the foundation that is necessary for future investigations of dune dynamics in contrasting environments. The key aspects of dune morphology, sediment transport, and flow that underpin the analysis are discussed below.

\section{BACKGROUND}

\section{Morphology: adaptation and equilibrium}

The definition of an equilibrium dune form fundamentally underpins our ability to predict bed roughness (Van Rijn, 1984; 1993). Past studies systematically emphasise that dune geometry is the product of a hydrodynamic dependency between dune form and the co-evolving flow field (see overviews in Bennett and Best, 1995, Best, 2005a; Coleman and Nikora, 2011). Dune height and wavelength are often assumed to scale with flow depth in rivers (Yalin, 1964; Ashley, 1990; Bradley and Venditti, 2017) and each dune is dynamically linked to its up- and down- stream counterparts (Best, 2005a; Schatz and Herrmann, 2006; Reesink and Bridge, 2009; Unsworth et al., in press). Such dependencies strongly imply that dune size can be predicted for rivers (Ashley, 1990; Allen, 1982; Naqshband et al., 2014b; Bradley and Venditti, 2017).

However, determining an equilibrium dune shape is difficult because natural dune populations contain a range of sizes and shapes (Nordin, 1971; Paola and Borgman, 1991; Leclair, 2002). The difficulties in defining dune 'equilibrium' have led to fundamental disagreements about the relative 
importance of i) steady-state variability inherent to stable dune populations (Nordin, 1971; Jackson 1976; Rubin and McCulloch, 1980; Paola and Borgman, 1991; Parsons et al., 2005) and ii) the inheritance of dune morphology from past flow events (Allen, 1982; Allen and Collinson, 1974), as controls on dune geometry.

Indeed, variability in dune shape may be caused by deformation of dunes as they migrate. Variability in shape is deemed intrinsic to sediment transport over dunes, and hence expected to also occur under equilibrium conditions (Venditti et al., 2005a; McElroy and Mohrig, 2009). Additional variability is introduced by the adaptation of dunes to changes in flow. Dune adaptation is ubiquitous because river flow is characteristically both unsteady and non-uniform at the temporal and spatial scales that are needed for dunes to reach equilibrium (Allen, 1978; Allen and Friend, 1976; Ten Brinke et al., 1999; Kleinhans et al., 2007). Further deviations from a simplified relationship between dune geometry and depth can be attributed to variables such as changes in viscosity, turbulence, and the shape of the velocity profile (e.g. Smith and Ettema, 1997), grain-size sorting and the development of coarse-grained pavements (Tuijnder et al., 2009; Rodrigues et al., 2015), sediment bypassing and suspension (Nittrouer et al., 2008, Szupiany et al., 2012; Naqshband et al., 2014a), Froude number and water surface interactions (Naqshband et al., 2014b), suspension of clays (Wan and Wang, 1994; Baas and Best, 2002; Baas et al., 2009, 2016), and cohesion of the bed (Schindler et al., 2015; Malarkey et al., 2015; Parsons et al., 2016).

It is important to stress that dunes are also rarely in equilibrium because any geometric change requires both time and sufficient sediment transport. The delayed development of dunes relative to their formative flow is known as dune hysteresis (e.g. Allen, 1974; Ten Brinke et al., 1999; Kleinhans et al., 2007; Martin and Jerolmack, 2013). Although such hysteresis is commonly described as a temporal lag between bed morphology and the formative flow, other studies suggest that the processes of growth and decay of dunes differ (e.g. Martin and Jerolmack, 2013). There is, therefore, a need to identify precisely which processes are involved in the growth and decay of dunes, and at what spatial and temporal scales these processes operate.

The rate at which dunes adapt to new flow conditions depends on the rate of sediment transport and is considered to decrease non-linearly towards an equilibrium state (Paarlberg et al., 2010; Martin and Jerolmack, 2013). Convergence of parameters such as bedform height, wavelength, steepness (e.g. Van der Mark et al., 2008) and 'deformation flux', which describes deformation as a proportion of downstream migration, may provide practical solutions for the definition of an equilibrium form (McElroy and Mohrig, 2009). However, simplifications of dune morphology to mean geometric parameters introduce a loss of information, and remain strictly valid for the conditions for which they were tested until the underlying processes are fully understood.

\section{Sediment transport: dispersal of sediment over and between dunes}

Dunes compete for space while migrating. In order for one dune to grow, another must reduce in size to accommodate this growth. Significant dune adaptation requires dunes to be added to, or removed from, the dune field, and this occurs through merging or splitting of dunes (Fig. 1A-B; Raudkivi and Witte, 1990; Coleman and Melville, 1994). The new merged or split dunes have heightlength ratios that differ significantly from their surrounding dunes (Fig. 1A-B, Flemming, 2000), which leads to spatial unevenness in the flow-form feedback processes within the dune field. As a consequence, the competition for space between dunes leads to the redistribution of sediment across the dune field. Any study of dune adaptation is therefore a study of sediment dispersal over and between dunes (Reesink et al., 2016).

The redistribution of sediment over and among dunes is controlled by multiple sediment transport processes (Fig. 1C-I). Bedload sediment can be suspended temporarily and therefore bypass one, or 
several, dunes (Fig. 1C; e.g. Jopling, 1965; Allen, 1982; Kostaschuk, et al., 2009; Naqshband et al., 2014a). Sediment transport paths are likely to vary in response to spatial and temporal variability in velocity and turbulence over dune fields (Allen, 1982; Reesink and Bridge, 2009). Indeed, field measurements of dune form and suspension of sand across bars and through bends show that rates of sediment bypass can vary across successive dunes (Nittrouer et al., 2008; Szupiany et al., 2012). Sediment dispersal can also be achieved through differential migration of dunes (Fig. 1D; Martin and Jerolmack, 2013), or by the introduction and storage of sediment by differential scour (Fig. 1E; Gabel, 1993; Leclair, 2002). Modification of dune shape may involve superimposition of bedforms (Fig. 1F; Best, 2005a; Fernandez et al., 2006), which has also been described as the mechanism by which sediment moves over host dunes (Ditchfield and Best, 1992; Venditti, 2005a). Bedform superimposition is also essential for the onset of bedform splitting (Gabel, 1993; Warmink et al., 2014) and essential to the through-passing of superimposed bedforms (Fig. 1G; Venditti et al., 2005b). The relative role of through-passing of smaller bedforms, as opposed to bypassing of suspended sediment, is likely a function of grain size and transport stage. The volume of sediment transported by dune migration can also be modified by changing dune geometry from a triangular profile to a humpback profile (Saunderson and Lockett, 1983; Carling et al., 2000; Reesink and Bridge, 2009). The magnitude of sediment transport is, however, not captured fully by simple metrics such as bedform height and wavelength, and is problematic in cases where changes in dune form and size indicate significant transfer of sediment between dunes (Ten Brinke et al., 1999; McElroy and Mohrig, 2009). Both bedform superimposition and changes in dune geometry affect the flow field over dunes (Fig. 1H; Best and Kostaschuk, 2002; Fernandez et al., 2006; Reesink and Bridge, 2009; Kwoll et al., 2016; Lefebvre et al., 2016) and hence the sediment transport dynamics (Reesink and Bridge, 2009). Finally, sediment can be dispersed in the cross-stream direction (Fig. 11; Allen, 1982), which is likely more pronounced when dunes have more variable three-dimensional geometries (Parsons et al., 2005). This can create strong local flow structures and affect the direction gravity-controlled grainflows, especially in cases where larger scale secondary circulation may exist in addition to the flow over the dunes.

The relative importance of the multitude of processes that disperse sediment over and among dunes changes in response to both grain size and bed shear stress (McElroy and Mohrig, 2009; Martin and Jerolmack, 2013; Venditti et al., 2016; Bradley and Venditti, 2017). Dune development is known to vary significantly over time, in space, and between different reaches of river channels (e.g. Kleinhans et al., 2007), with the instabilities in dune patterns being transferred through the dune field by means of flow-form feedback processes, which are expected to gradually dissipate (Werner and Kocurek, 1997, 1999; Venditti et al., 2005b; Ewing and Kocurek, 2010). However, the relative importance of individual processes remains poorly constrained. To begin to address these issues, the present paper investigates the response of dunes to changes in flow using new methods for the visualisation of dune deformation, which provides objective evidence for the analysis of the processes that control dune development (Reesink et al., 2016).

\section{Flow: depth and water surface slope}

The best-known hydrodynamic association between dune form and flow is the positive correlation between dune height and wavelength with water depth (Yalin, 1964; Ashley, 1990; Van Rijn, 1993; Bradley and Venditti, 2017). Despite the spatial complexity of dune fields in rivers and the systematic deviations from a simple correlation discussed earlier, the dependency of dunes on flow depth is at least, in part, supported by observations of dune growth during floods and by the presence of large dunes in large rivers (Amsler and Garcia, 1997; Julien and Klaassen, 1995; Wilbers and Ten Brinke, 1999; Best et al., 2007). It is therefore clear that the depth of the formative flow is an important control on dune adaptation. 
In most rivers, flow depth is correlated with discharge at individual gauging stations through rating curves, although the flow depth for a given discharge depends on the form roughness generated by the bed and bar forms (Simons and Richardson, 1966; Dawdy, 1965; Garcia, 2006; Van Rijn, 1993). Because dune adaptation changes bed roughness, dune height and flow depth are not strictly independent during the passage of floods. In flume experiments and numerical predictions of dune adaptation, flow depth, water surface slope, flow velocity, and discharge are often considered to be interdependent (Paarlberg et al., 2009; Martin and Jerolmack, 2013; Warmink et al., 2014; Nabi et al., 2015). Such simplifications are indeed justified for a considerable range of scales (Schumm, 1977).

However, the relative magnitudes of flow depth and water surface slope vary systematically in rivers at the spatial scale of the dune wavelength, and at the temporal scale required for dunes to migrate this distance. Temporally, the water depth and water-surface slope that drive sediment transport are out-of-phase during the passage of significant flood waves (Fig. 2). This is well-known for pronounced, symmetrical waves in simple tidal systems (Fig. 2A; e.g. Martinius and Van den Berg, 2011; Dalrymple et al., 2015), but is equally valid for non-tidal rivers in which flood waves are superimposed on the water-surface gradient that is associated with the baseflow discharge (Fig. 2B). The loop-like relation between water-surface slope and water depth (Fig. 2C) is significant even for relatively large rivers and floods that last for weeks, such as in the Mississippi (Fig. 3). The characteristic asymmetry of fluvial flood waves is clearly indicated by the larger number of days with decreased water-surface slopes (Fig. 3). Thus, not only are the relative magnitudes of slope and depth variable, but the relative duration of specific combinations of slope and depth will vary between environments, floods, and different locations along and within a river.

The relative magnitudes of flow depth and water-surface slope also vary spatially. Changes in flow depth and water surface slope between the thalweg and bar tops (Fig. 4A) result in variations in tractive forces, sediment transport, erosion and deposition (Bridge, 1993), similar to that which has been extensively investigated for pools and riffles (Carling, 1991; Sear, 1996; Milan et al., 2001). At a larger spatial scale across drainage basins, flow depth and water-surface slope vary between shallow and steep upstream channels, to deeper and lower-gradient lowland channels, to tidal channels (Fig. 4B; Leopold and Maddock, 1953). The consequences of such systematic variability in hydraulic variables for dune development remain poorly understood. The experiments conducted herein were thus designed to investigate the roles of water depth and velocity on the kinematics of dune development.

\section{METHODS}

In order to investigate the response of dunes to changes in water depth and flow velocity, a series of controlled experiments was designed in which measurements of flow velocity, water depth, and bathymetry were made in an experimental flume with a fully-mobile sediment bed. A series of novel analyses was developed to determine how the imposed changes in flow conditions affected the dune morphology and sediment redistribution. The experiments and analytical techniques are discussed below.

\section{Experimental set-up and measurements}

In the present experiments, fully-mobile dunes were developed in sand with median grain size of $240 \mu \mathrm{m}$ in a sediment-recirculating flume that was $16 \mathrm{~m}$ long, $2 \mathrm{~m}$ wide and $0.5 \mathrm{~m}$ deep, which was constructed in the Total Environment Simulator in The Deep Facility at the University of Hull, UK (Fig. 5). A flow baffle was placed at the upstream end of the channel to dissipate turbulence generated by the pumps and inlet to the flume (Fig. 5A). Additional slurry pumps were installed to prevent the 
build-up of sand within the recirculating loop (Fig. 5A). Flow depth and discharge were increased and decreased both independently and in unison (Table 1) within the known limits of dune stability (cf. Van den Berg and Van Gelder, 1993). The stage-discharge combinations correspond to Froude numbers ranging from 0.3 to 0.5 (Table 1 ) and overlap conditions used by Unsworth et al. (in press). This set-up produced bedforms that could be compared directly to those found in shallow natural sand-bed rivers without using any scaling relationships (Fig. 5B).

Changes in discharge were achieved using the flume pump, whilst water depth was changed via rapid addition or subtraction of water from the flume, into a set of ten Intermediary Bulk Containers (IBC's) of 1000 litres each. Water surface slope, flow velocity, bed shear stress, sediment transport, and Froude number responded to the changes in depth and discharge. The imposed changes in flow depth and velocity occurred faster (1-5 minutes depending on water volume) than the repetition rate of the bathymetric profiles ( 5 minutes). The changes in morphology are thus considered to be stepwise in comparison to the bathymetric profiles. A total of 24 stage-discharge combinations were explored (Table 1), resulting in 23 adaptations (Table 2). Each stage-discharge combination was maintained for as long as the dunes that existed at the start of the new conditions took to migrate through the flume test section. The replacement of the existing bed by a new dune bed that developed entirely under the new conditions took between 1.5 to 3 hours across all experiments.

Flow velocity, water level, and bathymetry were measured throughout the experiments in a $5 \mathrm{~m}$ long test section located in the centre of the flume (Fig. 5A). The depth-averaged flow velocity was measured using a set of four fixed Nortek acoustic Doppler velocimeters (ADV's) sampling at a rate of $25 \mathrm{~Hz}$. The measurements were made at $40 \%$ of the water depth from the bed at 4 locations in the test section, which, assuming the law-of-the-wall, provides a measure of the average flow velocity. Discharge was monitored using a built-in electromagnetic pipe gauge (Euromag MC106C). The development the dune morphology and bed elevation were measured along the centreline of the flume at 5 minute intervals using an AQUAscat ${ }^{\mathrm{TM}}$ acoustic backscatter probe operating at $4 \mathrm{MHz}$, which was mounted on a Stebon ${ }^{\mathrm{TM}} 6 \mathrm{~m}$ robotic traverse. The vertical and horizontal resolution of the acoustic backscatter measurements were 2.5 and $5 \mathrm{~mm}$ respectively, with the bed elevation being determined from the maximum amplitude of the acoustic backscatter return. Noise and spikes in the elevation data were filtered out using visually established elevation threshold values and a median filter. The data were then averaged to provide a value that corresponded to the experimental intervals, which are used herein as an average value only. Water depth and water-surface slope were measured along the test section at $2 \mathrm{~Hz}$ using 7 wave height probes (HR Wallingford WG8 Twinwire wave rod system) that were spaced $1 \mathrm{~m}$ apart and located $0.75 \mathrm{~m}$ from the centreline of the flume in order to enable the robotic carriage to move (Fig. 5A). The bed elevation measurements were corrected relative to the still-water level. The flume was drained slowly to minimise deformation of the sand bed after every four experimental runs in order to allow detailed scanning of the sand bed with a Terrestrial Laser Scanner to millimetre resolution (Leica ScanStation2).

\section{Analysis of dune adaptation}

In order to investigate the adaptation of dunes to imposed changes in flow, the analysis presented herein focusses on the dune longitudinal profiles from 0.5 hours prior to the imposed changes, until 1 hour after the imposed change (Fig. 6A;9). Most of the dunes migrated out of the $5 \mathrm{~m}$ long test section within this period. Therefore, beyond 1 hour, the dunes in the test section represented new dunes that developed downstream from the flow baffle under the new flow conditions, and do not represent dunes that were adapting to the imposed conditions. In addition, as the effect of any change in flow depth and velocity on dune morphology can be expected to decrease over time (Allen, 1974, 1982; Martin and Jerolmack, 2013), restricting the time period of the analysis allows focus on the role of the imposed flow changes and decreases inclusion of the role of variability that is inherent to the dune population. 
358 Mean heights and wavelengths of the primary dunes were defined based on their crossing of the mean bed elevation that was calculated over the entire length of the test section (Table 1; cf. Van der Mark et al., 2008). Although this objective method introduces some superimposed bedforms into the bedform distribution, visual inspection indicated that the method closely matches a subjective classification of the dunes. However, the simplification of dune shape to parameters such as dune wavelength and height does not provide sufficient evidence to interpret the processes that control dune deformation and adaptation. Therefore, changes in bed topography are further analysed in several complementary ways, which are discussed below: i) dune kinematics, including the gain and loss of the number of dunes, and bedform superimposition, ii) temporal changes in the bed elevation distribution, and iii) deformation of dunes as revealed by the residuals of crosscorrelated profiles (Reesink et al., 2016)

\section{Dune Kinematics: gain and loss of dunes, unstable dune patterns, and superimposed bedforms}

Kinematic analysis refers to the identification of interactions between dunes, which includes key adaptation processes such as bedform splitting, merging, overtaking, and dissipation (Gabel, 1993; Warmink, 2014). In order to analyse such dune kinematics, primary dunes first need to be defined and distinguished from other bedforms, and then dunes need to be traced across successive profiles in a systematic way in order to identify their appearance and disappearance.

Primary dunes can be distinguished from smaller-scale superimposed, ephemeral, incipient and decayed bedforms by considering their temporal development as well as their geometries (cf. Gabel, 1993; Bridge, 2003, p. 86-87). Herein, a primary dune is defined as an asymmetrical bedform $>0.05$ $\mathrm{m}$ high and $>0.2 \mathrm{~m}$ long that can be traced across at least three longitudinal profiles (herein $>15$ minutes). These criteria do not aim to distinguish between ripples and dunes, nor provide a method for the identification of the presence or absence or ripples (for ripple stability, see Kleinhans et al., 2017). Inherent to the practical definition used herein is a lower limit where the temporal and/or spatial resolution is insufficient for unambiguous identification of dunes. This practical limit constrains a class of spatially aliased, ephemeral, and/or superimposed bedforms that presents a useful indicator of the inability of the dune field to achieve a stable configuration by itself.

For the kinematic analysis, dunes were traced between profiles by outlining the positions of both the crests and troughs of the bedforms (Fig. 6B; cf. Allen and Friend, 1976, their fig. 1B). The interpretation of kinematic behaviour is acknowledged to be sensitive to the spatio-temporal resolution of the measurements. For example, what appears to be the dissipation of a dune may be dune overtaking revealed in a higher temporal resolution dataset. Therefore, kinematic interactions are herein simplified to: i) a gain in the number of dunes; ii) a loss in the number of dunes. The gain of dunes includes dune splitting, emergence of dunes, and the amalgamation of incipient forms that were not classified as dunes. Loss of dunes includes merging of dunes, overtaking of dunes, and dying out (Raudkivi and Witte, 1990; Gabel, 1993; Coleman and Melville, 1994; Warmink et al., 2014; Warmink, 2014). Significant spatial aliasing between profiles is interpreted as a separate case of interest: iii) instability within the dune pattern. Finally, the analysis of consecutive dune profiles makes it possible to make simple observations of temporal changes in dune geometry, including iv) the presence of trains of superimposed bedforms, and $v$ ) dune flattening.

\section{Bed elevation distributions}

Bed elevation distributions, as opposed to dune height distributions, can be considered to represent the average bed morphology (e.g. Coleman et al., 2011). The use of the bed elevation distribution is independent from the identification and classification of bedforms, which is beneficial in cases with complex and changing bed morphology. Herein, the bed elevation distribution is calculated for individual profiles and plotted over time as a grey-scale, relative to the median elevation (Fig. 6C). 
The temporal change in bed elevation distribution visualises changes in the mean bed form. In particular, superelevation of the bedform crest, where the top of a dune builds higher into the flow, and increased trough scour (e.g. Gabel, 1993) are readily visualised by widening of the distribution towards the top and/or bottom (Fig. 6C).

\section{Dune migration and deformation}

Recent work illustrates how the motion of bedload sediment transport over dune-covered river beds can be split, by means of cross-correlation, into two components: dune migration and dune deformation (McElroy and Mohrig, 2009; Reesink et al., 2016). In the present analysis, the migration of dunes is removed by shifting the longitudinal bed profiles according to the first downstream cross-correlation maximum (Fig. 7A; cf. McElroy and Mohrig, 2009). The cross-correlation shift is indicated by the blanking at the left side of the dune profiles and indicates the dune 'translation', or migration. The residuals of the cross-correlation illustrate spatial patterns in the deformation of the dunes: localised loss and gain of sediment within the mobile dune field (Fig. 7B). Plotting the deformation component for consecutive profiles thus visualises changes in spatial dune deformation over time (Fig. 7C) and allows the identification of persistent sources and sinks of sediment within the mobile dune field (Reesink et al., 2016). The visualization displays a complex pattern of deformation that requires further interpretation. Zones that are characterised by a dominant trend in deformation can be seen, such as that outlined in Figure 7C. Alternatively, geomorphically distinguishable elements, such as lee slopes, can be traced between profiles, and the loss or gain of sediment from these elements over time can be interpreted (Fig. 7C; red and blue lines). The hypothesis proposed herein is that these deformation patterns can be used as signatures for local dune adaptation processes, such as acceleration, deceleration, growth and decay (Fig. 7D). Processes such as bedform superimposition are likely associated with specific trends in the gain (blue) or loss (red) of sediment from their host dunes, resulting in patterns that can be analysed and classified (Fig. 7D). The analysis used herein is simplified after McElroy and Mohrig (2009) and does not present cross-correlation decay coefficients, deformation half-times, and deformation ratios, which proved less meaningful for the experimental results. This difference may be attributed to factors such as the result of limitations imposed by shorter profile length, different sampling interval times, higher mobility of the finer grain size, greater three-dimensional dune geometries, and the abundance of superimposed bedforms in the present experiments. In addition, the methods of McElroy and Mohrig (2009) are developed to quantify dune deformation in stable dune fields, and not for the analysis of distinctly unstable dune patterns and adaptation of dunes to changes in flow.

\section{RESULTS}

The bed elevation measurements of dune geometries and the laser scans of the bed at selected stage-discharge combinations (Fig. 8) illustrate that the size and geometry of the dunes varied between different flow conditions (Table 1). Water-surface slope (Table 1) was found to vary greatly in response to local dune morphology, and the times and distances required to establish reliable water-surface slopes exceeded those involved in the response of individual dunes to changes in flow. Overall, mean dune height in the experiments was $\sim 0.1 \mathrm{~m}$, and varied between $\sim 0.05 \mathrm{~m}$ in the shallowest water depths to $0.19 \mathrm{~m}$ in the greatest water depths. Superimposed bedforms were less common at higher flow velocities and lower water depths, and thus higher bed shear stresses. The largest dunes were found in deeper water and under higher shear stresses, in contrast to the smaller dunes in lower water depths and velocities (cf. Ashley, 1990; Van Rijn, 1993; Naqshband et al. 2014b; Bradley and Venditti, 2017). It is therefore expected that specific processes of deformation and adaptation of dunes (Fig. 1) were significantly enhanced or reduced by the imposed changes in flow depth and velocity, which was the aim of varying the flow stage in the experiments. 

The general trends in the bed morphology described above were complicated by significant variability in dune morphology and large numbers of superimposed bedforms (Fig. 9). Particularly prominent changes in dune morphology included the development of trains of superimposed bedforms (Fig. 9, Label S) and flattening of the dune profiles (Fig. 9, Label F). The development of persistent trains of superimposed bedforms was systematically associated with increased water depths and decreased flow velocities (Fig. 10A, Table 2), but was also linked to specific histories of local dune interactions. Trains of superimposed bedforms were found to develop after a dune was overtaken and dissipated into a trough (Fig. $9 d, h, m, n, p, r$, label S; Table 2). Such dissipation of a dune created an extra-long crest-to-crest distance within which the superimposed bedforms developed (Fig. 9). The association between trains of superimposed dunes and prior loss of an upstream dune was not necessarily found in the inverse situation: not all loss of dunes results in bedform superimposition.

Flattening of bedforms was more common following a decrease in water depth and an increase in flow velocity (Fig. 10B). No relation was observed between prior dune interactions and flattening of the dune profile. One case was found in which superimposition and flattening of the crest occurred at the same time on successive dunes (Fig. 9d).

In addition to systematic trains of superimposed bedforms on the stoss slope of a larger dune, superimposed bedforms were also found as solitary and short-lived forms throughout all experiments (Figs 9, 11). Furthermore, small bedforms were common in cases where dunes could not be traced between successive profiles. Such cases led to significant spatial aliasing in our dataset and were labelled as 'instability' of the dune field because the dunes were unable to establish a form of sufficient size and stability to be traced between profiles (e.g. Fig. 9, label U). Instability did not show a clear relation with the changes in flow conditions (Fig. 10C), but was associated with the lower post-change water depths and velocities (Fig. 10D).

\section{Interpretation}

The results indicate that systematically enhanced superimposition of bedforms (Fig. 1F) is characteristic for the adaptation of the dunes to increased depth and decreased flow velocity, whereas flattening of the dune profile (Fig. $1 \mathrm{H}$ ) is characteristic for decreased depth and increased flow velocity. The association of spatial aliasing between profiles, the definition of instability within the dune pattern, with post-change flow conditions being considered rather than the magnitude of change, may indicate that dunes potentially become unstable closer to the ripple-to-dune transition (Van den Berg and Van Gelder, 1993) and that smaller bedforms migrate faster in comparison to larger dunes for any given bedload transport rate. The observation that flattening and enhanced bedform superimposition can occur on successive dunes (Fig. 9d) supports the notion that local flow conditions dominate the precise mechanisms of local adaptation of dunes, thus allowing for significant variability in dune shape and process at any stage (Bridge, 1981).

The observation that trains of superimposed bedforms are associated with increased water depth and decreased flow velocity (clustering in Fig. 10A-B), and locally increased crest-to-crest distances (Fig. 9 label S) is consistent with the experiments of Reesink et al. (2014b) and model of Warmink et al. (2013), as well as observations of bedform superimposition in rivers during falling stages of floods (Wilbers and Ten Brinke, 2003; Kleinhans et al., 2007). The observation that superimposed bedforms (Fig. 10A) become 'washed-out' (Fig. 10B) following a decrease in water depth is supported by many studies of dune dynamics (Bridge, 1981; Saunderson and Lockett, 1983; Carling et al., 2000; Reesink and Bridge, 2009). However, the association of superimposition and flattening with increases and decreases in flow depth, respectively, presents an apparent contradiction: a decrease in water depth incites dune splitting in a trend towards a larger number of smaller dunes, but, dune splitting 
requires the development of a superimposed bedform, which is reduced following a decrease in water depth. This apparent contradiction - that the conditions that favour superimposition do not favour dune splitting by superimposed dunes, and vice versa - matches observations of pervasive superimposition on seemingly stable bedforms in natural rivers (Allen 1978; Rubin and McCulloch, 1980; Wilbers and Ten Brinke, 2003; Parsons et al., 2005) and suggests that dunes with abundant superimposed bedforms do not necessarily split into smaller dunes.

This contrast between conditions that favour dune splitting and those that favour the development of superimposed bedforms justifies the recognition of separate classes, and perhaps causes, of superimposition: i) solitary superimposed bedforms that are present throughout the experiments (Mantz, 1978; Bridge, 1981, 2003; Reesink and Bridge, 2009); ii) persistent trains of superimposed bedforms on stable host dunes (Fig. 9, Label S) and iii) the proliferation of small forms in cases where the host dunes are unable to establish a stable morphology. Although these three morphological classes may represent a continuum, their distinction was straightforward for the experimental results herein. Whereas the presence of trains of superimposed bedforms was associated with both overall and local flow conditions, the presence of occasional solitary superimposed bedforms on dunes (cf. Reesink and Bridge, 2009) and thin incipient forms (cf. Venditti et al., 2005) may be independent of flow conditions. These results indicate that the development of solitary superimposed bedforms, rather than the local development of systematic trains of superimposed bedforms, is responsible for dunes splitting.

\section{Dune kinematics: addition and loss of dunes from the profiles}

Tracing the crests and troughs of dunes between successive bed profiles makes it possible to discern the locations where dunes appear or disappear (Fig. 11, labels + and -). The vertical and horizontal spacing between the crests and troughs varied between profiles in response to changes in dune scour depth and the arrival of superimposed bedforms that modified the shapes of the dune crests and lee slopes. Individual bedform crests were indicated where bedforms could not be traced between successive profiles (Fig. 11, indicated by small circles). A count of the number of dunes lost from, or added to, the profiles provided a measure of dune kinematics (Table 2). The entry and exit of dunes from the test section were not included in this analysis. In the experiments, a total of 26 new dunes appeared within the dune profile after the imposed changes in flow as a consequence of splitting and the amalgamation of incipient bedforms that were not classified as dunes (Fig. 11, label + , Table 2). The gain of 26 dunes decreased in the downstream direction with 11, 7, 5, 2 and 1 dunes gained over the 5 metres of the test section. Moreover, 21 dunes were gained in shallower postchange depths $(0.17-0.185 \mathrm{~m})$ whereas only 5 dunes were gained in deeper post-change depths (0.19-0.23 m; Table 2). This association of the addition of small dunes in shallower flows was reflected by the clustering of gains of $>2$ dunes shown in Figure 12B. After the imposed changes in flow, 65 dunes were lost from the test section due to overtaking and merger / amalgamation of dunes, and the dissipation of dunes until the form was no longer traceable (Fig. 11, label -; Table 2). The dissipation of dunes in troughs was often associated with increased scour of the larger new trough (Fig. 9.). The loss of dunes from the profile did not show a clear relationship with downstream distance, post-change conditions, or the magnitude of change (Fig. 12A).

\section{Interpretation}

The addition and loss of dunes from the profiles provides clear evidence of dune adaptation because the lengthening and shortening of dunes requires dunes to either merge or split. Three key observations can be made. First, more (small) dunes were added to the profile following a decrease in water depth (Fig. 12B), reflecting the destruction of larger dunes in a trend towards smaller dunes that are in equilibrium with the reduced water depth (Ashley, 1990). 
Second, the gain in new (small) dunes was much less than the loss of small dunes to the construction of larger dunes. The splitting of large dunes into a larger number of smaller dunes also decreased in the downstream direction. This dominance of dune construction processes indicates that dunes continued to increase in wavelength throughout the test section. Dunes are known to first approach a stable height, and then continue to amalgamate and interact in a trend towards increasingly stable dune geometries (cf. Gabel et al., 1993; Leclair, 2002; Nabi et al., 2015). The count of gain and loss of the number of dunes indicates that dune stabilization continues throughout the test section, even after dune heights have converged. The analysis of dune loss versus gain provides a more sensitive measure of this continued stabilization than can be achieved through quantification of dune height

Third, whereas the gain of dunes displayed a downstream trend, the loss of dunes did not. This contrast indicates that the processes of growth and decay are not linearly related, which supports the contention that processes of bedform gain and loss differ fundamentally (cf. Martin and Jerolmack, 2013). The dominance of construction (loss of dunes) over destruction (gain of smaller dunes) also supports the idea that, once established, self-organising flow-form feedbacks stabilise the dunes and allow them to persist: amalgamating smaller bedforms generate new larger bedforms faster, and more easily, than large bedforms split (cf. Fredsøe, 1974; Allen and Friend, 1976; McLean, 1990; Bridge, 2003). The observed unevenness in the ease of bedform construction versus the delayed destruction of dunes is, in itself, a contributing factor to dune hysteresis.

\section{Analysis of bed elevation distributions}

Bed elevation distributions were determined for all profiles in order to provide an analysis of bed topography that was independent from the identification of dunes and their distinction from ripples, transitional bedforms, and ephemeral, incipient, and decayed dunes. When plotted over time, bed elevation distributions visualise the overall developments in dune geometry (Fig. 13). Asymmetrical patterns in the bed elevation distribution over time, in which crest elevation and trough scour develop at different times, were more common than symmetrical increases in bed amplitude where elevation changes occurred at the same time (Fig. 13). Such symmetrical patterns were observed when dunes developed from a low-amplitude bed elevation distribution or a near-flat bed. Superelevation of the dune crest above the average bed elevation distribution only lasted for 5-15 minutes and showed no relationship with changes in flow depth or velocity, although a weak association may exist with deeper post-change flow depths (Table 2; 5 of 8 occurrences in the deeper flows and 2 of 15 occurrences in shallow flows). No relationship was found between crest superelevation and flow velocity or Froude number that is linked to the drawdown of the water surface over the crests (Table 2). Contrary to the short-lived superelevation of the dune crests, increased trough scour typically persisted for 15-45 minutes and was associated preferentially with the highest post-change flow velocities (Fig. 13).

\section{Interpretation}

The analysis of the elevation distribution reveals that dune crests and troughs do not respond to changes in flow at the same time, they do not persist for the same length of time, and they do not respond in the same way to changes in depth and velocity. Whereas trough scour responded more to velocity, superelevation of the dune crest did not, and showed only a weak association with flow depth (Fig. 14). This contrast in the behaviour of crests and troughs matches basic considerations of flow acceleration and deceleration over the dunes. A small change in dune-crest elevation has a proportionally larger effect on flow acceleration over the crest in comparison to the effect of an increase in water depth over the trough. This effect explains the short-lived nature of superelevation of the crest and its preferential association with greater water depths, as opposed to flow velocity. The association of trough scour with greater downstream velocities matches the contention that increased velocity increases turbulence generated by the leeside flow separation shear layer, which 

2009).

The asymmetrical development of dune trough scour and crest superelevation matches previous crests and troughs are in conflict with the general rule that the largest dunes are responsible for the deepest scours and hence the formation and preservation of dune sets (Paola and Borgman, 1991; Leclair and Bridge, 2001). Instead, the relation of trough scour noted herein was often associated with prior dune dissipation (Fig. 9, label S), which suggests that deep scours may be related to interactions of dunes that locally enhance trough scour. Because dune interaction is more pronounced at select times during floods (cf. Martin and Jerolmack, 2013) and at certain locations in natural channels and flumes, the sedimentary record may reflect a more complex set of dune dynamics than merely dune size.

\section{Analysis of dune deformation (cross-correlation analysis)}

The residuals of the cross-correlation of successive profiles (Fig. 7A-B) were plotted in sequence (Fig. 7C) to visualise the temporal development of dune deformation in the experiment. This analysis successfully visualises zones of excess, or lack of, deposition relative to the downstream shift of the dune field (Fig. 15). The first observation is that dune deformation is significant, and both spatially and temporally variable. No significant increase in deformation in response to the imposed flow changes, or decrease over time, that would indicate a distinct re-equilibration is observed. Thus, continuous deformation of the dunes as they migrate through the flume dominated over a potential response in dune deformation related to the imposed changes.

The deformation pattern does not coincide neatly with the dune morphology, as may be expected because the technique separates local deformation of dune geometry from the average dune migration. The differences between dune shape and the magnitude of deformation indicate that the dunes in the experiments of this study change significantly in shape between successive profiles. Despite the complexity of the dune deformation pattern, the gain and loss of sediment is not random, and several, co-existing, deformation patterns can be discerned: 1) consistent zones of gain/loss of sediment that have downstream lengths comparable to the dune wavelength and that persist for 30-60 minutes (black dashed outlines in Fig. 7C and Fig. 15); 2) pronounced gain/loss of sediment from lee slopes over periods that may vary significantly in duration (red and blue lines in Fig. 7C and Fig. 15), and; 3) short-lived and short-wavelength zones of sediment gain/loss that are often not consistent between successive profiles. These three patterns are discussed below.

The first pattern, zones within which gain or loss dominates over downstream lengths $>0.5 \mathrm{~m}$ and in periods of time around 30-60 minutes, indicate persistent local sources (red) or sinks (blue) within the dune field (black dashed outlines in Figs 15). Systematic zones of sediment loss and deposition that span across a full dune were observed in cases where dunes dissipated (strict sense cf. Fig. 7D; Fig. 15, Label C) and where dunes grow considerably (strict sense cf. Fig. 7 D; Fig. 15, Label G). Furthermore, large zones of upstream loss and later downstream gain of sediment within the dune profile were associated with the development of superimposed bedforms. These occurrences commonly started when sediment was released locally during the decay of a dune in a trough (Fig. 15 , label $\mathrm{C}$, dominant red colour). The stoss slope that is located downstream from this decaying dune increases in length (crest-to-crest distance) as a result of the prior dune decay. The lengthened stoss slope is observed to slow down relative to the overall dune migration, which is indicated by its net gain of sediment (Fig. 15, dominant blue colour). The upstream edge of the zone of sediment gain moves downstream in accordance with the decelerated trough. The zone of sediment gain rapidly widens, and then decreases in magnitude over time (Fig. 15, dashed black outlines 
surrounding blue colour). The onset of a relative gain of sediment on the downstream lee slope is followed by development of superimposed bedforms within the zone of sediment gain (Fig. 6A and Fig. 15h, label S). The temporal development of these zones of sediment gain varies (Fig. 15, Label S, dashed black outlines) and may contain internal variability in deformation related to the development of smaller superimposed bedforms (e.g. Fig. 15h and $\mathrm{m}$ ). This sequence of associated processes involves successive dunes rather than being limited to a single dune.

Zones of sediment loss or gain that span an entire dune indicate the decay or growth of this dune (strict sense cf. Fig. 7D). Dune decay (Fig. 15, label C; Table 2) was more common than growth (Fig. 15, label G; Table 2), which matches earlier observations of the dominance of the loss of dunes over the gain of dunes. Dune decay was found for most flow conditions (Table 2) and could therefore not be associated with a preferential subset of flow conditions. Dune growth was preferentially associated with increased flow velocities, but because only five clear cases were observed for three flow conditions (Table 2), and other runs with similar flow conditions did not yield comparable results.

The second apparent pattern is the loss or gain of sediment from lee slopes (Fig. 15, blue and red lines), although not all lee slopes displayed this pattern. Areas of gain or loss of sediment often extended from the lee slope onto the crest or into the trough. The trend in sediment gain or loss could also change half-way down the lee slopes in cases where the shapes of the adjacent crests and troughs changed significantly. Variation in the magnitude of the gain or loss of sediment from the lee slope was commonly linked to the arrival of superimposed bedforms. The arrival of superimposed bedforms, however, did not necessarily change the character of the lee slope from gain to loss of sediment, or vice versa. In other words, superimposed bedforms were seen to affect, but not dominate, the deposition of sediment on the host lee slope. Sediment gain on lee slopes can indicate growth or acceleration of a dune, and sediment loss from lee slopes can indicate its decay or deceleration (Fig. 7D).

The gain or loss of sediment from the lee slopes persisted for longer (5-60 minutes; Fig. 13; blue and red lines) than clear cases of dune acceleration and deceleration (strict sense cf. Fig. 7D), which require the concurrent movement of both stoss and lee slopes (5-20 minutes; Fig. 15, labels A and D). Acceleration and deceleration of dunes and local growth and decay were common throughout the experiments (Table 2). These dynamics could follow one another temporally on a single dune (Fig. 15 e, $k, l, m$ ), and could occur at the same time on successive dunes (Fig. 13 h, k,l, u). Acceleration was common for all changes in flow conditions, and deceleration showed only a slight preference for deeper flows and lower flow velocities (Table 2).

The third pattern, short-wavelength, short-lived zones of gain or loss of sediment were commonly linked to the presence of superimposed bedforms. However, not all short-lived zones of gain or loss of sediment on dune lee slopes were associated with superimposed bedforms that were easily recognised by the presence of a superimposed stoss and lee slope. Thus, the method also visualises superimposed bedforms on dunes that were incorporated within the dune profile rather than distinguishable based on their own morphology. No clear cases were found in which systematic zones of net gain of sediment (Fig. 15, red colour) were transferred across successive dunes, which would be the expected deformation signature for the through-passing of bedforms (Venditti et al., 2005b). However, it is possible that the temporal resolution of successive profiles in these experiments was not sufficient to reliably resolve this process.

\section{Interpretation of dune deformation}

The above analysis shows that colouring successive profiles according to the residuals of crosscorrelation visualises successfully the local gain or loss of sediment within the mobile dune field (Figs 
$7,15)$. No appreciable change in the magnitude of deformation was found in relation to the imposed changes in flow, indicating that adaptation did not significantly enhance deformation relative to the migration of the bedforms. Additionally, it is likely that deformation associated with the downstream development of dunes as they migrated through the flume dominated any increase of deformation induced by imposed changes in flow depth and velocity. The previous sections indicate, however, that individual processes did change systematically in both magnitude and frequency. The deformation pattern that is revealed illustrates that the deformation of dunes is significant and highly variable across the dune profiles, as well as over time. To guide the interpretation of this new visualisation of dune deformation, three patterns are highlighted.

The first pattern, zones of relative gain or loss of sediment that persist systematically within the mobile dune field, can be interpreted as local sources and sinks of sediment: they attract or shed sediment as the dunes migrate downstream. Zones of systematic gain of sediment on stoss slopes appear to be associated with the development of trains of superimposed bedforms. It is important to emphasise that such a 'gain' is relative to the motion of the dune field, and presents a decrease in erosion of the stoss slope rather than net deposition or upstream migration. The development of trains of bedforms within zones of sediment gain highlight that: i) defects within a dune field are dissipated over time as sediment is dispersed across dunes, and ii) the dissipation of defects within a dune field occurs through a series of associated processes rather than a single mechanism.

The second pattern, sediment loss and gain on lee slopes, is pronounced because the largest volume of deposition occurs on the lee slope, and this creates the largest potential for relative changes in deposition. The variability in relative deposition on lee slopes emphasises the importance of differential migration (Fig. 1 D; cf. Martin and Jerolmack, 2013), although the lee slope alone is not evidence for acceleration or deceleration of dunes (cf. Fig. 7D). Dune acceleration and deceleration were predominantly short-lived, which reflects that dunes are pinned in place by the flow to their upstream and downstream counterparts. The results thus indicate that, rather than 'jostling for position without coalescing' (Coleman and Melville, 1994, p555), significant transfer of sediment occurs between dunes.

The loss of sediment commonly extends beyond the lee slope onto the adjacent crest and/or trough. Decreased deposition on the lee slope directly downstream from a dune crest that is losing sediment (Fig. 15, red colour) is a signature that is likely associated with bypassing of sediment, and hence transfer of sediment between dunes (Naqshband et al., 2014a). Decreased deposition on a lee slope upstream from a trough that is deepening likely reflects the continuation of sediment transport in the trough while the lee slope receives little sediment, such as is the case when the trough of a superimposed bedform reaches the crest of its host dune (Fernandez et al., 2006; Reesink and Bridge, 2007, 2009).

This final pattern, short-lived local variations in gain or loss of sediment that are often aliased spatially between successive profiles, was commonly associated with the presence of superimposed bedforms. Thus, the results highlight the importance of bedform superimposition as a control on sediment redistribution over successive dunes. The abundance of short-lived local variability, as well as partial growth, decay, splitting, and merger found in these experiments highlights that the dunes are far less stable than would be inferred from their traditional description as individual entities. Critically, this analysis illustrates that dune deformation is dominated by dune-to-dune interactions that occur on spatial scales of 0.1 to $2 \mathrm{~m}$ and temporal scales of several minutes to hours. These scales are too large and long-lasting to be linked to individual coherent flow structures and too small to be the sole product of imposed flow conditions: dune deformation thus reflects a multitude of form-flow feedback processes that operate between the scales of turbulence and those at which average flow parameters are established. 


\section{DISCUSSION}

The adaptation of dunes to changes in flow is the end-product of multiple, simultaneous processes that redistribute sediment over and among dunes (Fig. 1). The same sediment redistribution processes are also responsible for the steady-state deformation of dunes (see McElroy and Mohrig, 2009). The present study illustrates that this sediment redistribution is pervasive, and hence dunes are far more interconnected than has been commonly acknowledged when treating them as individual and measurable entities.

Although the present experiments with mobile dunes in shallow flows (depth 0.17-0.25 m) indicate that many of the individual processes involved in the deformation of dunes respond in their own unique way to changes in flow velocity and depth. Although these finding are in line with those of detailed flow quantifications by Unsworth et al. (in press), the development of quantification or predictive models would be premature based on the present dataset. The fully-mobile sand-bed experiments presented herein include significant spatial and temporal variability in flow, bed morphology, and adaptation processes, and the data represent two-dimensional slices through dunes that possess a three-dimensional character. Nonetheless, the new tools for analysis and visualisation of changes in dune morphology presented herein provide the basis for a series of unique observations with important implications for the way we consider the spatial variability in dune geometry, dune development and hysteresis, the form-flow equilibrium of subaqueous dunes, and sediment transport over dunes.

\section{Dune morphology responds differently to changes in flow depth and velocity}

The results of the present experimental study of dunes in shallow flows (depth 0.17-0.25 m) confirm that the adaptation of dunes, and the manner in which sediment is redistributed across the form, is not a simple function of sediment transport rates (Allen 1982). Instead, different geometric signatures were observed for dunes adapting to changes in water depth and flow velocity. Six main findings are apparent:

i) In the experiments, the magnitude of dune deformation (Figs 7, 15) did not change systematically directly following the imposed change in flow. The absence of a clear change in the magnitude of deformation is partially attributed to the limited ranges of flow depth and velocity in the experiments. Instead of a significant change in the magnitude of deformation, adaptation occurred through systematic changes in the processes that controlled the redistribution of sediment over and across dunes (Fig. 1).

ii) Trough scour (Fig. 14A) increased following an increase in velocity, and was linked to local dune interactions and bedform overtaking.

iii) Flattening of the dune crest (Fig. 10B) increased following an increase in flow velocity and/or a decrease in water depth.

iv) The development of trains of superimposed bedforms was associated with an increase in flow depth and a decrease in flow velocity (Fig. 10A) and was linked to prior decay of an upstream dune. This dune decay created an increased crest-to-crest distance, and led to the deceleration (relative to the surrounding dunes) of the stoss slope on which the superimposed bedforms developed.

v) Acceleration and deceleration, and growth and decay of dunes, were common in most experimental runs and showed no clear association with changes in flow depth or velocity (Table 2), although their magnitudes may vary depending on flow conditions (Martin and Jerolmack, 2013). 
vi) Instability of the dune pattern, indicated by spatial aliasing between successive profiles, was more common in shallow flows (Fig. 10D) and was unaffected by the direction or magnitude of change (Fig. 10C).

Thus, dune adaptation processes differ for changes in flow depth and velocity, and may be dominated by: 1) the imposed change in the flow conditions, 2) the post-change flow conditions, and 3) local form-flow feedback processes.

\section{Temporal variability in dune adaptation: types of hysteresis}

The present study highlights that the complex nature of dune development is subject to at least three different types of hysteresis: 1) apparent hysteresis created by a temporal lag in response of dunes to the flow, 2) true hysteresis in which growth and decay are caused by fundamentally different processes, and 3) a hysteresis of the driving variables created by the out-of-phase relation between water depth and velocity during the passage of flood waves (Figs 2, 3, 16).

The best known form of hysteresis is the temporal development lag or 'apparent hysteresis', in which the redistribution of sediment over and among dunes takes time, such that bedform adaptation lags behind relative to the change in flow (Allen, 1973, 1974, 1982; Julien and Klaassen, 1995; Wilbers et al., 2003; Shimizu et al., 2009). In addition, the present study and recent work by Martin and Jerolmack (2013) suggests that the processes of dune growth and decay differ fundamentally. The results presented herein support the notion that dunes prolong their existence through the development of a persistent separated flow in their lee, which is, by itself, a cause of hysteresis (Fredsøe, 1974; Allen and Friend, 1976; McLean, 1990). When the loop-like relation between dune form and flow is a consequence of fundamentally different processes, this is known as 'true hysteresis'. The distinction between true and apparent hysteresis is particularly important because apparent hysteresis can be modelled as a function of sediment transport and would reflect dunes in all environments (Allen, 1973, 1974), whereas true hysteresis requires a more complex treatment of different growth and decay mechanisms. The present study emphasises the importance of simultaneous processes of sediment re-distribution (Fig. 1), which have a specific preference for rising or falling flow stages because they relate differently to flow depth and velocity. Finally, water depth and the water-surface slope that drives the flow velocity are out-of-phase during the passage of flood waves (Fig. 14). This out-of-phase relation between water depth and water-surface slope during flood waves can be seen as a 'hysteresis of the driving variables' (Figs 2, 3).

The systematic, out-of-phase changes in water depth and flow velocity during the passage of flood waves will result in systematically altered behaviour of the dunes, which is summarised as a conceptual diagram (Fig, 16). Morphological responses, such as flattening of the dune crest (e.g. Carling et al., 2000), increased trough scour (e.g. Gabel, 1993), and the development of trains of superimposed bedforms, were associated with specific depth-velocity combinations, and should therefore vary in a similar fashion during the passage of a flood wave in a straight, shallow channel. The passage of successive flood waves will result in cyclic repetition of these processes of dune growth and decay, which is expected to be predictable for individual locations, but not necessarily transferable between locations because of spatial variability in the controls on dune adaptation.

\section{Spatial and environmental variability in dune adaptation}

The hydraulic controls on dune adaptation vary spatially within and between depositional environments. In river channels, water depth and water surface slope vary spatially between the thalweg and bar tops, across bends, along the catchment from the headwaters, through lowland rivers and the backwater zone to tidally-influenced reaches (Fig. 4; Leopold and Maddock, 1953; Knighton, 1999). Locally, flow depth and velocity vary dramatically in their relative magnitude from 
the thalweg to bar tops (Fig. 4). This may be most apparent when considering the abandonment of dunes on bar-tops, in oxbow lakes, and in bar troughs (Reesink et al., 2015). It may be expected that the processes shown in Figure 16 need to be reviewed critically when this conceptual model of cyclic dune development is applied to different areas within river channels. The controlling parameters also vary systematically along rivers. In particular, the main channels of the world's largest rivers are characterised by deep flows and low water-surface slopes. This combination of hydraulic parameters that control dune development provides an explanation for differences in the behaviour of dunes in Klaassen, 1995; Amsler and Garcia, 1997).

The shapes of flood waves also vary between rivers. The large annual floods in monsoon-cyclone systems such as the Mekong River (Darby et al., 2016) are likely to contrast with more asymmetrical flood waves in the Mississippi River that respond to snow melt, rainfall, and groundwater recharge (Fig. 3). Whereas the absolute magnitude of the floods determines the absolute and relative changes in depth and velocity, the asymmetry of the flood wave determines the relative duration of various stages of the out-of-phase cycle of depth and water surface slope (Fig. 16). For example, the common observation of cannibalization of host dunes by smaller superimposed dunes (e.g. Pretious and Blench, 1951; Julien and Klaassen, 1995; Wilbers et al., 2003; Kleinhans et al., 2007) may become more pronounced with longer duration waning stages of floods.

The results of the present study show that dune adaptation varies in response to different controlling parameters (e.g. depth, velocity, viscosity, magnitudes of change, gravitational acceleration). The hydraulic controls are even more variable when non-fluvial environments, such as estuaries, shallow-marine zones, submarine density currents, and aeolian deserts are considered. Thus, the summary of the experimental results depicted in Fig. 16 does not necessarily describe dunes in deep flows, or dunes in tidal and tidally-influenced channels, where frequent flow reversals and changes in velocity affect the dynamic development of dunes. Although the similarity in the form of asymmetrical sandy bedforms in different environments suggests that overarching principles can be identified, the results shown herein suggest that the processes that control dune adaptation need to be compared and contrasted between different locations and environments.

\section{Equilibration of dunes: from local interactions to long-distance transfer}

Dune height is known to develop faster than dune wavelength (cf. Gabel, 1993; Leclair, 2002), and this contention is further supported by the present results. After mean dune height and wavelength achieve stable values, the equilibration of dunes continues by means of kinematic interactions, which continued throughout the entire length of the present mobile bed experiments. Some deformation processes were found to generate others. For example, dissipation of a dune was commonly followed by the appearance of superimposed bedforms on the downstream dune stoss slope. The transfer of sediment through chains of associated processes introduces an important problem: the trend towards equilibrium dune geometries requires merging and splitting of dunes (Fig. $1 \mathrm{~A}, \mathrm{~B}$ ), which generates local instabilities within the dune field that then need to be dissipated. Indeed, even after stable dune heights and wavelengths have been attained, "jostling for position without coalescing" is known to continue (Coleman and Melville, 1994, p.555). The visualisation and analysis of dune deformation illustrated herein illustrates that this jostling is a proliferation of interactions between dunes, rather than spatial re-adjustment of dunes that maintain their size and shape. The size and abundance of sources and sinks of sediment within the dune field will likely decrease as dunes approach their equilibrium geometry, and a change will necessarily take place from local interactions to longer-distance transfer of excess sediment over increasingly stable dunes. Thus, the present study provides a framework for the interpretation of quantitative data from bedload sampling (e.g. Emmett, 1979) and acoustic measurements of bedload velocity and concentration (Rennie et al., 2002; Kostaschuk et al., 2009; Naqshband et al., 2014a). Sediment 
transport over dune-covered river beds is perhaps better described as the sum of changing, local, form-flow interactions, rather than a steady flux that is set by reach-averaged flow conditions.

\section{New methods for investigating the dynamic development of dunes}

Whereas the quantification of characteristic dune heights and wavelengths (Van der Mark et al., 2008) provides a sound basis for estimates of mean bed roughness, the reduction of complex dune patterns into simple descriptors hinders detailed analyses of the many form-flow feedback processes that control dune development. In order to avoid oversimplification of the initial evidence, four complementary methods that highlight different aspects of dune development are presented herein, each with its own merit and drawbacks. The visual classification of aspects of dune morphology (Figs 6,9 ) is easy, but may be sensitive to subjective interpretation. The quantification of dune kinematics through counting of the gain and loss of dunes (Figs 6,11 ) is easy and objective, but also combines different morphodynamic processes (see Gabel, 1993; Warmink et al., 2014) that may well respond differently to changes in flow and the evolution of the surrounding bed morphology. The use of a bed-elevation distribution (Figs 6,13 ) is an objective way to assess dune morphology, but is sensitive to the size of the area of measurement, superimposition of bedforms and the presence of largerscale bed forms. The visualisation of bed deformation by plotting the residuals of a cross-correlation between successive dune profiles (Figs 7,15 ) has been shown to be a practical method for generating objective evidence of the dynamic development of dunes. However, determining its full value and limitations will require further application to data from a wide range of contrasting environments such as rivers, estuaries, oceans and deserts.

\section{CONCLUSIONS}

The present study illustrates how dunes adapt to changes in a unidirectional flow. Dunes compete for space as they grow or decay in response to changing flow depth and velocity, and this creates local sources and sinks of sediment within the mobile dune field. These local instabilities induce significant sediment redistribution over, and between, dunes, which occurs through multiple, simultaneously acting processes. Dune adaptation is a spatially- and temporally-variable response of multiple, interacting dunes.

The present illustrate that dunes respond differently to changes in flow depth and velocity in the present shallow experimental flows. The most prominent morphological responses include: i) an increase in bedform superimposition following an increase in depth and velocity, ii) the flattening of dunes in response to decreased flow depth, and iii) an increase in scour in response to increased flow velocity. Variation in the response of dunes to changes in flow depth and velocity is particularly important, because the magnitude of flow depth and velocity vary systematically over time during floods, and spatially across and along river channels.

The analyses developed herein provide a new, objective, basis for the analysis of the processes that control the dynamic development of bedforms in the temporally and spatially complex flows of different environments on Earth as well as other planetary bodies.

\section{ACKNOWLEDGMENTS}

This research was supported by grant NE/I014101/1 from the UK Natural Environment Research Council (NERC). Data can be accessed by contacting A. Reesink. The manuscript has been improved significantly based on the thorough and constructive reviews of prof. Stéphane Rodrigues and prof. Burghard Flemming, for which we are very grateful. 


\section{REFERENCES}

Allen, J. R. L., 1973. Phase differences between bed configuration and flow in natural environments, and their geological relevance. Sedimentology, 20(2), 323-329, doi:10.1111/j.13653091.1973.tb02054.x.

Allen, J. R. L., 1974. Reaction, relaxation and lag in natural sedimentary systems: General principles, examples and lessons. Earth Sci. Rev., 10(4), 263-342. https://doi.org/10.1016/00128252(74)90109-3

Allen, J. R. L., 1978. Polymodal dune assemblages: An interpretation in terms of dune creationdestruction in periodic flows. Sediment. Geol., 20, 17-28. https://doi.org/10.1016/00370738(78)90046-5

Allen, J. R. L., Friend, P. F., 1976. Relaxation time of dunes in decelerating aqueous flows. J. Geol. Soc. London, 132(1), 17-26. https://doi.org/10.1144/gsigs.132.1.0017

Allen, J. R. L., Collinson, J. D. 1974. The superimposition and classification of dunes formed by unidirectional aqueous flows. Sedimentary Geology, 12(3), 169-178. https://doi.org/10.1016/0037-0738(74)90008-6

Allen, J.R.L., 1982. Sedimentary Structures, their Character and Physical Basis, volumes 1- 2. Developments in Sedimentology 30 a \& b. Elsevier Scientific Publishing Company, Amsterdam.

Almeida, R. P., Galeazzi, C. P., Freitas, B. T., Janikian, L., lanniruberto, M., Marconato, A., 2016. Large barchanoid dunes in the Amazon River and the rock record: Implications for interpreting large river systems. Earth and Planetary Science Letters, 454, 92-102. https://doi.org/10.1016/i.epsl.2016.08.029

Amsler, M.L. and Garcia, M.H., 1997. Sand-dune geometry of large rivers during floods - Discussion. J. Hydraul. Eng., 123, 582-585.

Ashley, G. M., 1990. Classification of large-scale subaqueous bedforms: a new look at an old

Baas, J. H., and Best, J. L., 2002. Turbulence modulation in clay-rich sediment-laden flows and some implications for sediment deposition. Journal of Sedimentary Research, 72(3), 336-340. doi: 10.1306/120601720336

Baas, J. H., Best, J. L., Peakall, J., \& Wang, M., 2009. A phase diagram for turbulent, transitional, and laminar clay suspension flows. Journal of Sedimentary Research, 79(4), 162-183.

Baas, J.H., Best, J.L. and Peakall, J. 2016. Predicting bedforms and primary current lamination in cohesive mixtures of mud and sand, J. Geological Society of London., 173, 12-45, doi: 10.1144/jgs2015-024.

Bennett, S. J., and Best, J. L., 1995. Mean flow and turbulence structure over fixed, two-dimensional dunes: Implications for sediment transport and bedform stability. Sedimentology, 42(3), 491513. DOI:10.1111/j.1365-3091.1995.tb00386.x

Bennett, S.J. \& Best, J.L. 1996. Mean flow and turbulence structure over fixed ripples and the rippledune transition. In: Coherent flow structures in open channels, (Eds: Ashworth, P.J., Bennett, S.J., Best, J.L. and M-Lelland, S.J.), Wiley and Sons, 281-304.

Best, J.L. 1993 On the interactions between turbulent flow structure, sediment transport and bedform development: some considerations from recent experimental research. In: Turbulence: perspectives on flow and sediment transport, (Eds: Clifford, N., French, J.R. and Hardisty, J), 6192. Wiley and Sons.

Best, J.L. 1996 The fluid dynamics of small-scale alluvial bedforms. In: Advances in Fluvial Dynamics and Stratigraphy (Eds: Carling, P.A. and Dawson, M.), 67-125, Wiley and Sons.

Best, J., 2005a. The fluid dynamics of river dunes: A review and some future research directions. Journal of Geophysical Research: Earth Surface,110(F4). DOI:10.1029/2004JF000218

Best, J. L., 2005b. Kinematics, topology and significance of dune-related macroturbulence: some observations from the laboratory and field. Fluvial sedimentology VII, 35, 41-60. 
Best, J., and Kostaschuk, R. 2002. An experimental study of turbulent flow over a low-angle dune. Journal of Geophysical Research: Oceans, 107(C9). DOI: 10.1029/2000JC000294

Best, J.L., Ashworth, P.J., Sarker, M.H. and Roden, J.E., 2007. The Brahmaputra-Jamuna River, Bangladesh. In: Large Rivers; Geomorphology and Management (Ed. A. Gupta), pp. 395-430. John Wiley \& Sons Ltd, Chichester.

Best, J., Simmons, S., Parsons, D., Oberg, K., Czuba, J., Malzone, C., 2010. A new methodology for the quantitative visualization of coherent flow structures in alluvial channels using multibeam echosounding (MBES). Geophysical Research Letters, 37(6). DOI: 10.1029/2009GL041852

Blom, A., Ribberink, J. S., and de Vriend, H. J., 2003. Vertical sorting in bed forms: Flume experiments with a natural and a trimodal sediment mixture. Water Resources Research, 39(2). DOI: 10.1029/2001WR001088

Blom, A., Parker, G., Ribberink, J. S., and De Vriend, H. J., 2006. Vertical sorting and the morphodynamics of bed-form-dominated rivers: An equilibrium sorting model. Journal of Geophysical Research: Earth Surface,111(F1). DOI: 10.1029/2004JF000175

Bradley RW, Venditti JG., 2017. Reevaluating dune scaling relations. Earth-Science Reviews, 165, 356-376. https://doi.org/10.1016/i.earscirev.2016.11.004

Bridge, J. S., 1981. Bed shear stress over subaqueous dunes, and the transition to upper-stage plane beds. Sedimentology, 28(1), 33-36. DOI: 10.1111/j.1365-3091.1981.tb01660.x

Bridge, J. S. 1993. The interaction between channel geometry, water flow, sediment transport and deposition in braided rivers. Geological Society, London, Special Publications, 75(1), 13-71. https://doi.org/10.1144/GSL.SP.1993.075.01.02

Bridge, J.S., 2003. Rivers and Floodplains; Forms, Processes, and Sedimentary Record. Blackwell Publishing, Oxford, U.K., 600 pp.

Carling, P. A., 1991. An appraisal of the velocity-reversal hypothesis for stable pool-riffle sequences in the River Severn, England. Earth Surface Processes and Landforms, 16(1), 19-31. DOI: 10.1002/esp.3290160104

Carling PA, Golz E, Orr HG, Radecki-Pawlik A., 2000. The morphodynamics of fluvial sand dunes in the River Rhine, near Mainz, Germany. I. Sedimentology and morphology. Sedimentology, 47(1):22752. DOI: 10.1046/j.1365-3091.2000.00290.x

Church, M., Ferguson, R. I., 2015. Morphodynamics: Rivers beyond steady state. Water Resources Research, 51(4), 1883-1897. DOI: 10.1002/2014WR016862

Claude, N., Rodrigues, S., Bustillo, V., Bréheret, J.-G.,Macaire, J.-J., Jugé, P., 2012. Estimating bedload transport in a large sand-gravel bed river from direct sampling, dune tracking and empirical formulas. Geomorphology 179, 40-57. https://doi.org/10.1016/j.geomorph.2012.07.030

Coleman, S. E., and Melville, B. W., 1996. Initiation of bed forms on a flat sand bed. Journal of Hydraulic Engineering, 122(6), 301-310. https://doi.org/10.1061/(ASCE)07339429(1996)122:6(301)

Coleman, S. E., and Nikora, V. I., 2011. Fluvial dunes: initiation, characterization, flow structure. Earth Surface processes and landforms,36(1), 39-57. DOI: 10.1002/esp.2096

Coleman, S. E., Nikora, V. I., and Aberle, J., 2011. Interpretation of alluvial beds through bedelevation distribution moments. Water Resources Research, 47(11). DOI: 10.1029/2011WR010672

Cutts, J. A., and Smith, R. S. U., 1973. Eolian deposits and dunes on Mars. Journal of Geophysical Research, 78(20), 4139-4154. DOI: 10.1029/JB078i020p04139

Dalrymple, R.W., Kurcinka C.E., Jablonski B.V.J., Ichaso A.A., Mackay D.A., 2015. Deciphering the relative importance of fluvial and tidal processes in the fluvial-marine transition. in Ashworth, P.J., Best, J.L., and Parsons D.R. (Eds.) Fluvial Tidal Sedimentology, Advances in Sedimentology Vol. 68. Elsevier.

Darby, S. E., Hackney, C. R., Leyland, J., Kummu, M., Lauri, H., Parsons, D. R., Best, J.L., Nicholas, A.P., Aalto, R., 2016. Fluvial sediment supply to a mega-delta reduced by shifting tropical-cyclone activity. Nature, 539(7628), 276-279. doi:10.1038/nature19809 
Dawdy, D. R., 1965. Discontinuous depth-discharge relations for sand-channel streams and their effect on sediment transport. In Proceedings of the Federal Inter-Agency Sedimentation Conference, 1963 (No. 970, p. 309). US Department of Agriculture.

Diniega, S., Krevalevsky, M., Radebaugh, J., Silverstro, S., Telfer, M., Tirsch, D., 2016. Our evolving understanding of aeolian bedforms, based on observation of dunes on different worlds. Aeolian Research. https://doi.org/10.1016/j.aeolia.2016.10.001

Ditchfield, R., and Best, J., 1992. Discussion of “Development of Bed Features" by Arved J. Raudkivi and Hans-H. Witte (September, 1990, Vol. 116, No. 9). Journal of Hydraulic Engineering, 118(4), 647-650.

Emmett, W. W. 1979. A field calibration of the sediment-trapping characteristics of the Helley-Smith bedload sampler (Vol. 1139). US Government Printing Office.

Ewing, R. C., \& Kocurek, G. A. 2010. Aeolian dune interactions and dune-field pattern formation: White Sands Dune Field, New Mexico. Sedimentology, 57(5), 1199-1219. DOI: 10.1111/j.13653091.2009.01143.x

Fernandez, R., Best, J., López, F., 2006. Mean flow, turbulence structure, and bed form superimposition across the ripple-dune transition. Water Resources Research, 42(5). DOI: 10.1029/2005WR004330

Flemming, B. W., and Bartholomä, A. 2012. Temporal variability, migration rates and preservation potential of subaqueous dune fields generated in the Agulhas Current on the southeast African continental shelf. Sediments, Morphology and Sedimentary Processes on Continental Shelves: Advances in Technologies, Research, and Applications, 229-247.

Flemming, B. W. 2000. The role of grain size, water depth and flow velocity as scaling factors controlling the size of subaqueous dunes. In Marine Sandwave Dynamics, international workshop (pp. 23-24).

Fredsøe, J. 1974. On the development of dunes in erodible channels. Journal of Fluid Mechanics, 64(01), 1-16. DOI: https://doi.org/10.1017/S0022112074001960

Frings, R. M., Kleinhans, M. G., 2008. Complex variations in sediment transport at three large river bifurcations during discharge waves in the river Rhine. Sedimentology, 55(5), 1145-1171. DOI: 10.1111/j.1365-3091.2007.00940.x

Gabel, S. L., 1993. Geometry and kinematics of dunes during steady and unsteady flows in the Calamus River, Nebraska, USA. Sedimentology, 40(2), 237-269. DOI: 10.1111/j.13653091.1993.tb01763.x

García, M.H., 2006. ASCE Manual of Practice 110-Sedimentation Engineering: Processes, Measurements, Modeling and Practice. https://doi.org/10.1061/40856(200)94

Giri, S., Shimizu, Y., 2006. Numerical computation of sand dune migration with free surface flow. Water Resources Research, 42(10). DOI: 10.1029/2005WR004588

Hoey, T. B., Ferguson R., 1994. Numerical simulation of downstream fining by selective transport in gravel bed rivers: Model development and illustration, Water Resour. Res., 30(7), 2251-2260, doi:10.1029/94WR00556.

Jerolmack, D. J., Mohrig, D., 2005. Frozen dynamics of migrating bedforms. Geology, 33(1), 57-60. https://doi.org/10.1130/G20897.1

Jackson, R. G., 1975. Velocity-bed-form-texture patterns of meander bends in the lower Wabash River of Illinois and Indiana. Geological Society of America Bulletin, 86(11), 1511-1522. https://doi.org/10.1130/0016-7606(1975)86<1511:VPOMBI>2.0.CO;2

Jackson, R. G., 1976. Large scale ripples of the lower Wabash River. Sedimentology, 23(5), 593-623. DOI: $10.1111 /$ j.1365-3091.1976.tb00097.x

Jopling, A. V., 1965. Hydraulic factors controlling the shape of laminae in laboratory deltas. Journal of Sedimentary Research, 35(4).

Julien, P. Y., and Klaassen, G. J. 1995. Sand-dune geometry of large rivers during floods. Journal of Hydraulic Engineering, 121(9), 657-663. https://doi.org/10.1061/(ASCE)07339429(1995)121:9(657) 
Julien, P. Y., Klaassen, G. J., Ten Brinke, W. B. M., Wilbers, A. W. E., 2002. Case study: bed resistance of Rhine River during 1998 flood. Journal of Hydraulic Engineering, 128(12), 1042-1050. https://doi.org/10.1061/(ASCE)0733-9429(2002)128:12(1042)

Kleinhans, M. G., 2004. Sorting in grain flows at the lee side of dunes. Earth-Science Reviews, 65(1), 75-102. https://doi.org/10.1016/S0012-8252(03)00081-3

Kleinhans, M. G., Wilbers, A. W. E., Ten Brinke, W. B. M., 2007. Opposite hysteresis of sand and gravel transport upstream and downstream of a bifurcation during a flood in the River Rhine, the Netherlands. Netherlands Journal of Geosciences/Geologie en Mijnbouw, 86(3).

Kleinhans, M. G., Leuven, J. R. F. W., Braat, L., Baar, A. 2017. Scour holes and ripples occur below the hydraulic smooth to rough transition of movable beds. Sedimentology, 64(5), 1381-1401, doi:10.1111/sed.12358

Knighton, A. D., 1999. Downstream variation in stream power. Geomorphology, 29(3), 293-306. https://doi.org/10.1016/S0169-555X(99)00015-X

Kocurek, G., and Ewing, R. C., 2005. Aeolian dune field self-organization-implications for the formation of simple versus complex dune-field patterns. Geomorphology, 72(1), 94-105. https://doi.org/10.1016/i.geomorph.2005.05.005

Kostaschuk, R., Shugar, D., Best, J., Parsons, D., Lane, S., Hardy, R., Orfeo, O., 2009. Suspended sediment transport and deposition over a dune: Río Paraná, Argentina. Earth Surface Processes and Landforms, 34(12), 1605-1611. DOI: 10.1002/esp.1847

Kwoll, E., Venditti, J. G., Bradley, R. W., and Winter, C., 2016. Flow structure and resistance over subaquaeous high-and low-angle dunes. Journal of Geophysical Research: Earth Surface 121, 545-564 DOI: 10.1002/2015JF003637

Leclair, S. F., Bridge, J. S., 2001. Quantitative interpretation of sedimentary structures formed by river dunes. Journal of Sedimentary Research, 71(5), 713-716.

Leclair, S. F. 2002. Preservation of cross-strata due to the migration of subaqueous dunes: an experimental investigation. Sedimentology, 49(6), 1157-1180 DOI: 10.1046/j.13653091.2002.00482.x

Leeder, M.R., 1983. On the interactions between turbulent flow, sediment transport and bedform mechanics in channelized flows. In: Collinson, J.D., and Lewin, J., eds., Modern and ancient fluvial systems: IAS Special Publications 6, 5-18. DOI: 10.1002/9781444303773.ch1

Lefebvre, A., Paarlberg, A. J., Winter, C., 2016. Characterising natural bedform morphology and its influence on flow. Geo-Marine Letters, 1-15. DOI 10.1007/s00367-016-0455-5

Leopold, L. B., Maddock, T., 1953. The hydraulic geometry of stream channels and some physiographic implications (Vol. 252). US Government Printing Office.

Malarkey, J., Baas, J.H., Hope, J.A., Aspden, R.J., Parsons, D.R., Peakall, J., Paterson, D.M., Schindler R.J., Ye L., Lichtman I.D., Bass, S.J., Davies A.G, Manning A.J, Thorne P.D., 2015. The pervasive role of biological cohesion in bedform development. Nature communications, 6. doi: $10.1038 /$ ncomms 7257

Mantz, P. A. (1978). Bedforms produced by fine, cohesionless, granular and flakey sediments under subcritical water flows. Sedimentology, 25(1), 83-103. DOI: 10.1111/j.1365-3091.1978.tb00302.x

Martin, R. L., Jerolmack, D. J., 2013. Origin of hysteresis in bed form response to unsteady flows. Water Resources Research, 49(3), 1314-1333. DOI: 10.1002/wrcr.20093

Martinius, A. W., and Van den Berg, J. H. 2011. Atlas of sedimentary structures in estuarine and tidally-influenced river deposits of the Rhine-Meuse-Scheldt system (p. 298). EAGE.

McElroy, B., Mohrig, D., 2009. Nature of deformation of sandy bed forms. Journal of Geophysical Research: Earth Surface, 114(F3). DOI: 10.1029/2008JF001220

McLean, S. R., 1990. The stability of ripples and dunes. Earth-Science Reviews, 29(1), 131-144. https://doi.org/10.1016/0012-8252(0)90032-Q

Milan, D. J., Heritage, G. L., Large, A. R. G., and Charlton, M. E., 2001. Stage dependent variability in tractive force distribution through a riffle-pool sequence. Catena, 44(2), 85-109. https://doi.org/10.1016/S0341-8162(00)00155-7 
Nabi, M., Vriend, H. J., Mosselman, E., Sloff, C. J., Shimizu, Y., 2013. Detailed simulation of morphodynamics: 3. Ripples and dunes. Water resources research,49(9), 5930-5943. DOI: $10.1002 /$ wrcr.20457

Nabi, M., Kimura, I., Hsu, S. M., Giri, S., Shimizu, Y., 2015. Computational modeling of dissipation and regeneration of fluvial sand dunes under variable discharges. Journal of Geophysical Research: Earth Surface,120(7), 1390-1403. DOI: 10.1002/2014JF003364

Naqshband, S., Ribberink, J. S., Hurther, D., and Hulscher, S. J. M. H., 2014a. Bed load and suspended load contributions to migrating sand dunes in equilibrium. Journal of Geophysical Research: Earth Surface, 119(5), 1043-1063. DOI: 10.1002/2013JF003043

Naqshband, S., Ribberink, J. S., and Hulscher, S. J., 2014b. Using both free surface effect and sediment transport mode parameters in defining the morphology of river dunes and their evolution to upper stage plane beds. Journal of Hydraulic Engineering, 140(6), 06014010. https://doi.org/10.1061/(ASCE)HY.1943-7900.0000873

Nelson, J. M., McLean, S. R., Wolfe, S. R., 1993. Mean flow and turbulence fields over twodimensional bed forms. Water Resources Research,29(12), 3935-3953. DOI: 10.1029/93WR01932

Nittrouer, J. A., Allison, M. A., Campanella R., 2008. Bedform transport rates for the lowermost Mississippi River, J. Geophys. Res., 113, F03004, doi:10.1029/2007JF000795.

Nordin, C. F., 1971. Statistical properties of dune profiles. Geological Survey Professional Paper No. 562-F.

Omidyeganeh, M., Piomelli, U., 2011. Large-eddy simulation of two-dimensional dunes in a steady, unidirectional flow. Journal of Turbulence, (12), N42. http://dx.doi.org/10.1080/14685248.2011.609820

Omidyeganeh, M., Piomelli, U., 2013a. Large-eddy simulation of three-dimensional dunes in a steady, unidirectional flow. Part 1. Turbulence statistics. Journal of Fluid Mechanics, 721, 454. https://doi.org/10.1017/jfm.2013.3

Omidyeganeh, M., Piomelli, U., 2013b. Large-eddy simulation of three-dimensional dunes in a steady, unidirectional flow. Part 2. Flow structures. Journal of Fluid Mechanics, 734, 509534. https://doi.org/10.1017/ifm.2013.499

Paarlberg, A. J., Dohmen-Janssen, C. M., Hulscher, S. J., Termes, P., 2009. Modeling river dune evolution using a parameterization of flow separation. Journal of Geophysical Research: Earth Surface, 114(F1). DOI: 10.1029/2007JF000910

Paarlberg, A. J., Dohmen-Janssen, C. M., Hulscher, S. J., Termes, P., and Schielen, R. (2010). Modelling the effect of time-dependent river dune evolution on bed roughness and stage. Earth Surface Processes and Landforms, 35(15), 1854-1866. DOI: 10.1002/esp.2074

Paola, C., Borgman, L., 1991. Reconstructing random topography from preserved stratification. Sedimentology, 38(4), 553-565. DOI: 10.1111/j.1365-3091.1991.tb01008.x

Parsons, D. R., Best, J. L., Orfeo, O., Hardy, R. J., Kostaschuk, R., Lane, S. N., 2005. Morphology and flow fields of three-dimensional dunes, Rio Paraná, Argentina: Results from simultaneous multibeam echo sounding and acoustic Doppler current profiling. Journal of Geophysical Research: Earth Surface, 110(F4). DOI: 10.1029/2004JF000231

Parsons, D. R., Schindler, R. J., Hope, J. A., Malarkey, J., Baas, J. H., Peakall, J., Manning A.J., Ye L., Simmons S., Paterson D.M., Aspden. R.J., Bass, S.J., Davies, A.G., Lichtman, I.D., Thorne, P.D., 2016. The role of biophysical cohesion on subaqueous bed form size. Geophysical research letters, 43(4), 1566-1573. DOI: 10.1002/2016GL067667

Pretious, E. S., \& Blench, T., 1951. Final report on special observations on bed movement in the lower Fraser River at Ladner Reach During the 1950 freshet. National Research Council of Canada.

Raudkivi, A. J., Witte, H. H., 1990. Development of bed features. Journal of Hydraulic Engineering, 116(9), 1063-1079. https://doi.org/10.1061/(ASCE)0733-9429(1990)116:9(1063) 
Reesink, A. J. H., Bridge, J. S., 2007. Influence of superimposed bedforms and flow unsteadiness on formation of cross strata in dunes and unit bars. Sedimentary Geology, 202(1), 281-296. https://doi.org/10.1016/i.sedgeo.2007.02.005

Reesink, A. J., Bridge, J. S., 2009. Influence of bedform superimposition and flow unsteadiness on the formation of cross strata in dunes and unit bars-Part 2, further experiments. Sedimentary Geology, 222(3), 274-300. https://doi.org/10.1016/j.sedgeo.2009.09.014

Reesink, A. J., Bridge, J. S., 2011. Evidence of bedform superimposition and flow unsteadiness in unitbar deposits, South Saskatchewan River, Canada. Journal of Sedimentary Research, 81(11), 814840. doi: 10.2110/jsr.2011.69

Reesink A.J.H., Ashworth P.J. Sambrook Smith G.H., Best J.L., Parsons D.R., Amsler M.L., Hardy R.J., Lane S.N., Nicholas A.P., Orfeo O.O., Sandbach S.D., Simpson C.J., Szupiany R.N., 2014. Scales and causes of heterogeneity in bars in a large multi-channel river: Río Paraná, Argentina. Sedimentology, 61(4), p. 1055-1085. DOI: 10.1111/sed.12092

Reesink A.J.H., Parsons D.R., Thomas R.E., 2014. Sediment transport and bedform development in the lee of bars: Evidence from fixed-and partially-fixed bed experiments. River Flow 2014, Conference Proceedings

Reesink, A. J. H., Van den Berg, J. H., Parsons, D. R., Amsler, M. L., Best, J. L., Hardy, R. J., Szupiany, R. N., 2015. Extremes in dune preservation: Controls on the completeness of fluvial deposits. EarthScience Reviews, 150, 652-665. https://doi.org/10.1016/i.earscirev.2015.09.008

Reesink A.J.H., Parsons D.R., Ashworth P.J., Best J.L., Darby S.E., Hardy R.J., 2016. Visualising dune deformation and sediment dispersal across dune fields. Proceedings of the Marine and River Dunes conference 2016

Rennie, C. D., Millar, R. G., \& Church, M. A., 2002. Measurement of bed load velocity using an acoustic Doppler current profiler. Journal of Hydraulic Engineering, 128(5), 473-483. https://doi.org/10.1061/(ASCE)0733-9429(2002)128:5(473)

Rodrigues, S., Mosselman, E., Claude, N., Wintenberger, C. L., Juge, P., 2015. Alternate bars in a sandy gravel bed river: generation, migration and interactions with superimposed dunes. Earth Surface Processes and Landforms, 40(5), 610-628. DOI: 10.1002/esp.3657

Rubin, D. M., McCulloch, D. S., 1980. Single and superimposed bedforms: a synthesis of San Francisco Bay and flume observations. Sedimentary Geology, 26(1-3), 207-231. https://doi.org/10.1016/0037-0738(80)90012-3

Saunderson, H. C., and Lockett, F. P., 1983. Flume experiments on bedforms and structures at the dune-plane bed transition. In Modern and Ancient Fluvial Systems (Vol. 6, pp. 49-58). International Association of Sedimentologists.

Schatz, V., and Herrmann, H. J., 2006. Flow separation in the lee side of transverse dunes: a numerical investigation. Geomorphology, 81(1), 207-216. https://doi.org/10.1016/i.geomorph.2006.04.009

Schindler, R.J., Parsons, D.R., Ye, L., Hope, J.A., Baas J.H., Peakall, J., Manning, A.J., Aspden, R.J., Malarkey, J., Simmons, S., Paterson, D.M., Lichtman, I.D., Davies, A.G., Thorne, P.D., Bass S.J., Sticky stuff: Redefining bedform prediction in modern and ancient environments. Geology 2015; 43 (5): 399-402. doi: 10.1130/G36262.1

Schmeeckle, M. W., 2014. Numerical simulation of turbulence and sediment transport of medium sand. Journal of Geophysical Research: Earth Surface,119(6), 1240-1262. DOI: $10.1002 / 2013 J F 002911$

Schmeeckle, M. W., 2015. The role of velocity, pressure, and bed stress fluctuations in bed load transport over bed forms: numerical simulation downstream of a backward-facing step. Earth Surface Dynamics, 3(1), 105. doi:10.5194/esurf-3-105-2015

Schumm, S. A., 1977. The fluvial system. John Wiley and Sons, New York. 338p.

Schumm, S. A., 1998. To Interpret the Earth: Ten ways to be wrong. Cambridge University Press. $133 p$. 
Sear, D. A. (1996). Sediment transport processes in pool-riffle sequences. Earth Surface Processes and Landforms, 21(3), 241-262. DOI: 10.1002/(SICI)1096-9837(199603)21:3<241::AIDESP623>3.0.CO;2-1

Shimizu, Y., Giri, S., Yamaguchi, S., \& Nelson, J., 2009. Numerical simulation of dune-flat bed transition and stage-discharge relationship with hysteresis effect. Water Resources Research, 45(4). DOI: 10.1029/2008WR006830

Simons, D. B., Richardson, E. V., 1966. Resistance to flow in alluvial channels (p. 61). Geological Survey Professional Paper 422-J, Washington, DC: US Government Printing Office.

Smith, B. T., and R. Ettema (1997), Ice-cover influence on flow structure over dunes Ice-cover influence on flow structure over dunes, J. Hydraulic Research, 35(5), 37-41.

Szupiany, R. N., Amsler, M. L., Hernandez, J., Parsons, D. R., Best, J. L., Fornari, E., and Trento, A. 2012. Flow fields, bed shear stresses, and suspended bed sediment dynamics in bifurcations of a large river. Water Resources Research, 48(11). DOI: 10.1029/2011WR011677

Ten Brinke, W. B. M., Wilbers, A. W. E., and Wesseling, C. 1999. Dune Growth, Decay and Migration Rates during a Large-Magnitude Flood at a Sand and Mixed Sand-Gravel Bed in the Dutch Rhine River System. Fluvial sedimentology VI, 15-32. DOI: 10.1002/9781444304213.ch2

Thomas, N., B. Davidsson, M. R. El-Maarry, S. Fornasier, L. Giacomini, A. G. Gracia-Berná, S. F. Hviid, W.-H. Ip, L. Jorda, H. U. Keller, J. Knollenberg, E. Kührt, F. La Forgia, I. L. Lai, Y. Liao, R. Marschall, M. Massironi, S. Mottola, M. Pajola, O. Poch, A. Pommerol, F. Preusker, F. Scholten, C. C. Su, J. S. Wu, J.-B. Vincent, H. Sierks, C. Barbieri, P. L. Lamy, R. Rodrigo, D. Koschny, H. Rickman, M. F. A'Hearn, M. A. Barucci, J.-L. Bertaux, I. Bertini, G. Cremonese, V. Da Deppo, S. Debei, M. de Cecco, M. Fulle, O. Groussin, P. J. Gutierrez, J.-R. Kramm, M. Küppers, L. M. Lara, M. Lazzarin, J. J. Lopez Moreno, F. Marzari, H. Michalik, G. Naletto, J. Agarwal, C. Güttler, N. Oklay C. Tubiana Knollenberg, J., 2015. Redistribution of particles across the nucleus of comet 67P/ChuryumovGerasimenko. Astronomy and Astrophysics, 583, A17. doi:10.1051/0004-6361/201526049.

Tuijnder, A. P., Ribberink, J. S., Hulscher, S. J., 2009. An experimental study into the geometry of supply-limited dunes. Sedimentology, 56(6), 1713-1727. DOI: 10.1111/j.1365-3091.2009.01054.x

Unsworth, C.A., Parsons, D.R., Hardy, R.J., Reesink, A.J.H., Best, J.L., Ashworth, P.J., and Keevil, G.M. In press. The impact of non-equilibrium flow on the structure of turbulence over river dunes. Water Resources Research

Van den Berg, J.H., Van Gelder, A. 1993. A new bedform stability diagram, with emphasis on the transition of ripples to plane bed in flows over fine sand and silt. Alluvial Sedimentation (Special Publication 17 of the IAS),66, 11.

Van der Mark, C. F., Blom, A., and Hulscher, S. J. M. H., 2008. Quantification of variability in bedform geometry. Journal of Geophysical Research: Earth Surface, 113(F3). DOI: 10.1029/2007JF000940

Van Rijn, L. C., 1984. Sediment transport, part III: bed forms and alluvial roughness. Journal of hydraulic engineering, 110(12), 1733-1754. https://doi.org/10.1061/(ASCE)07339429(1984)110:12(1733)

Van Rijn, L. C., 1993. Principles of sediment transport in rivers, estuaries and coastal seas (Vol. 1006). Amsterdam: Aqua publications.

Venditti, J. G., Church, M., and Bennett, S. J., 2005a. Morphodynamics of small-scale superimposed sand waves over migrating dune bed forms. Water resources research, 41(10). DOI: 10.1029/2004WR003461

Venditti, J. G., Church, M., and Bennett, S. J., 2005b. On the transition between 2D and 3D dunes. Sedimentology, 52(6), 1343-1359. DOI: 10.1111/j.1365-3091.2005.00748.x

Venditti, J. G., Lin, C. Y. M., and Kazemi, M., 2016. Variability in bedform morphology and kinematics with transport stage. Sedimentology 63, 1017-1039. DOI: 10.1111/sed.12247

Wan, Z., Wang, Z., 1994. Hyperconcentrated Flow. In: Balkema, A.A. (Ed.) Brookfield, VT, p. 290.

Warmink, J. J., Straatsma, M. W., Huthoff, F., Booij, M. J., and Hulscher, S. J. M. H., 2013. Uncertainty of design water levels due to combined bed form and vegetation roughness in the Dutch River Waal. Journal of flood risk management, 6(4), 302-318. 
Warmink, J. J., Dohmen-Janssen, C. M., Lansink, J., Naqshband, S., Duin, O. J., Paarlberg, A. J., Termes, P., Hulscher, S. J. 2014. Understanding river dune splitting through flume experiments and analysis of a dune evolution model. Earth surface processes and landforms, 39(9), 12081220. DOI: $10.1002 /$ esp.3529

Warmink, J. J., 2014. Dune dynamics and roughness under gradually varying flood waves, comparing flume and field observations. Advances in geosciences, 39, 115-121. doi:10.5194/adgeo-39-1152014

Werner, B. T., and Kocurek, G., 1997. Bed-form dynamics: Does the tail wag the dog? Geology, 25(9), 771-774. https://doi.org/10.1130/0091-7613(1997)025<0771:BFDDTT>2.3.CO;2

Werner, B. T., and Kocurek, G., 1999. Bedform spacing from defect dynamics. Geology, 27(8), 727-

730. https://doi.org/10.1130/0091-7613(1999)027<0727:BSFDD >2.3.CO;2

Wilbers, A. W. E., Ten Brinke, W. B. M., 2003. The response of subaqueous dunes to floods in sand and gravel bed reaches of the Dutch Rhine. Sedimentology, 50(6), 1013-1034. DOI: 10.1046/j.1365-3091.2003.00585.x

Yalin M.S., 1964. Geometrical properties of sand waves. Journal of the Hydraulics Division, American Society of Civil Engineers 90(5), 105-119. 


\section{A. Merging}

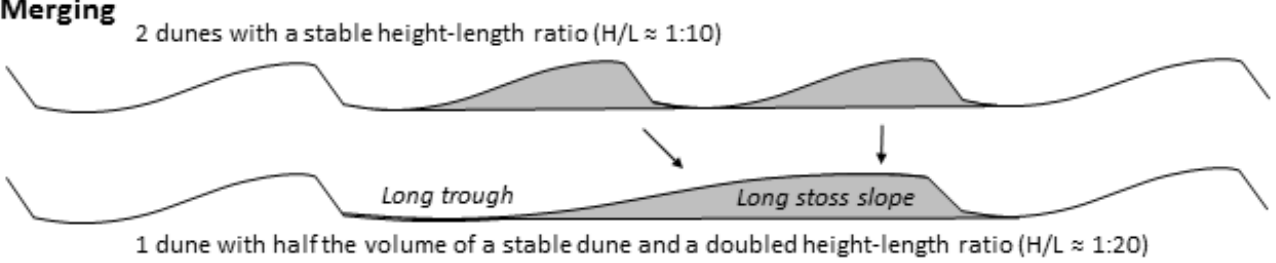

B. Splitting

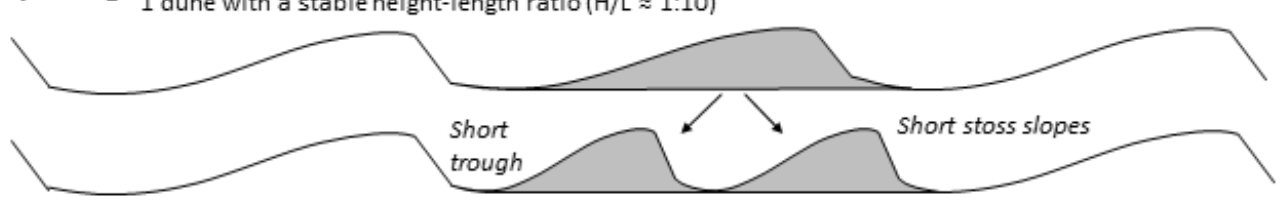

2 dunes with half the height-length ratio and a doubled volume of a stable dune $(H / L \approx 1: 5)$

\section{Bypassing of bedload}

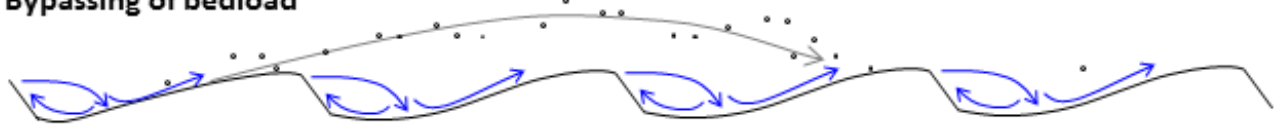

\section{Differential migration}

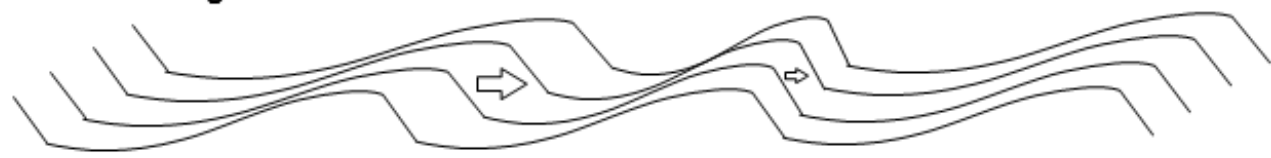

\section{E. Differential scour}

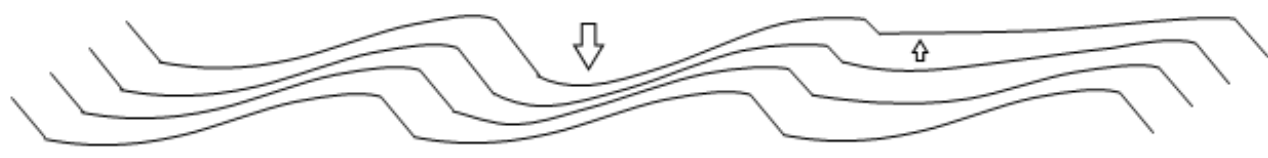

\section{F. Superimposition of bedforms}

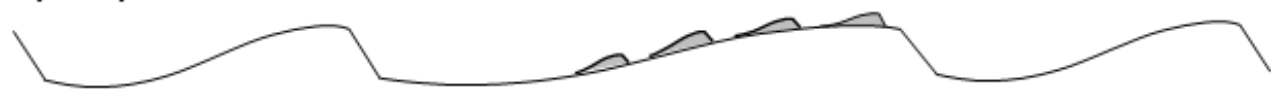

G. Through-passing of superimposed bedforms

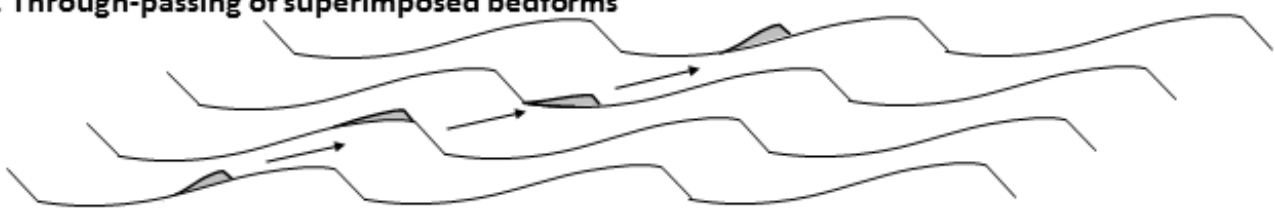

\section{H. Geometric change}

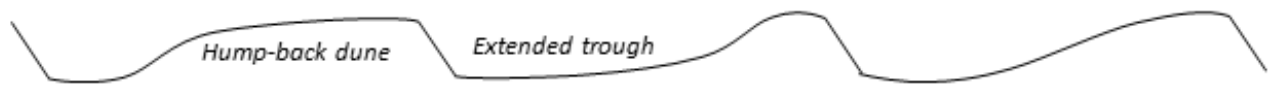

\section{Cross-stream sediment transfer}

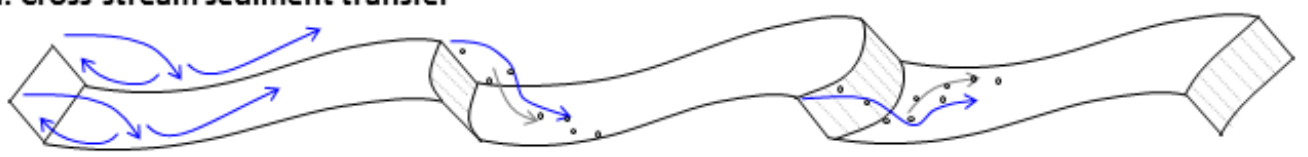

Figure 1. A-B The generation of local sources and sinks of sediment within a dune field by merging and splitting of dunes. C-I Sediment transport processes that may contribute to the dispersal of sediment across a dune field. Blue arrows indicate flow paths and directions. 
A

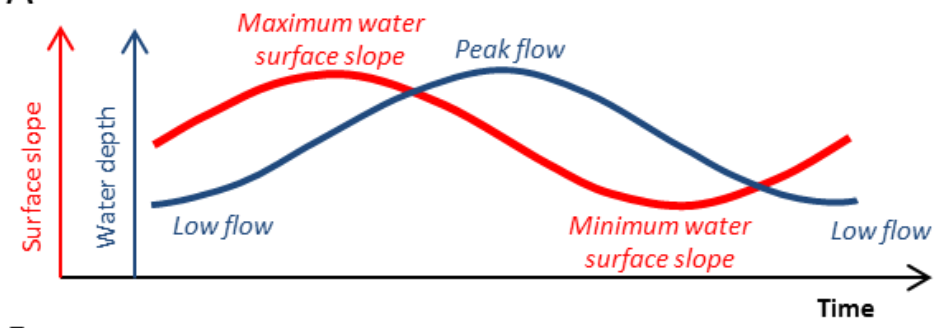

B

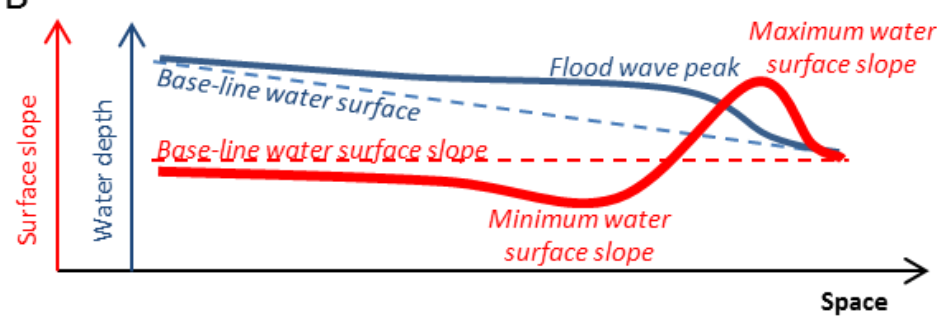

C

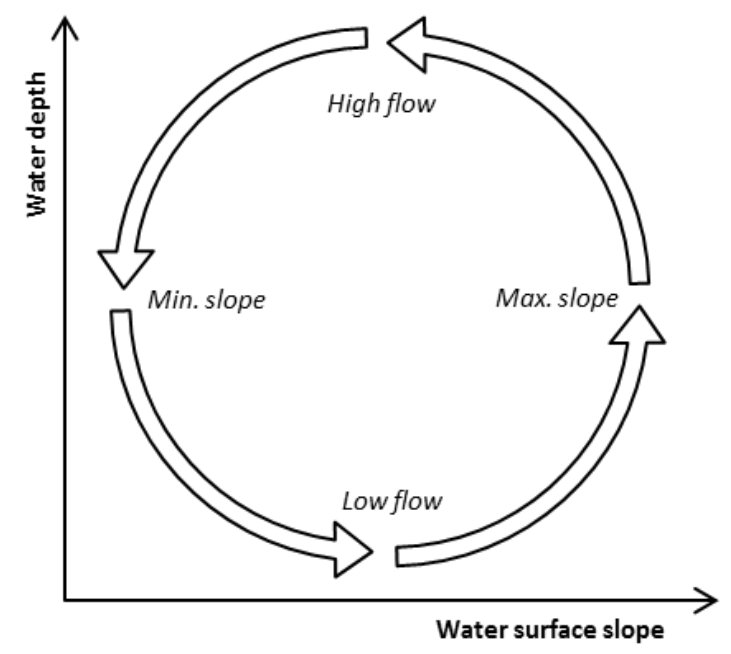

Figure 2. Depth and water-surface slope associated with flood waves is out-of-phase over time and in space, as illustrated here for: A) a simple symmetrical wave at a point over time, and B) for a single time along the length of a non-tidal river. C) The out-of-phase relation between depth and slope creates a cycle in depth and slope that is repeated for successive floods. 


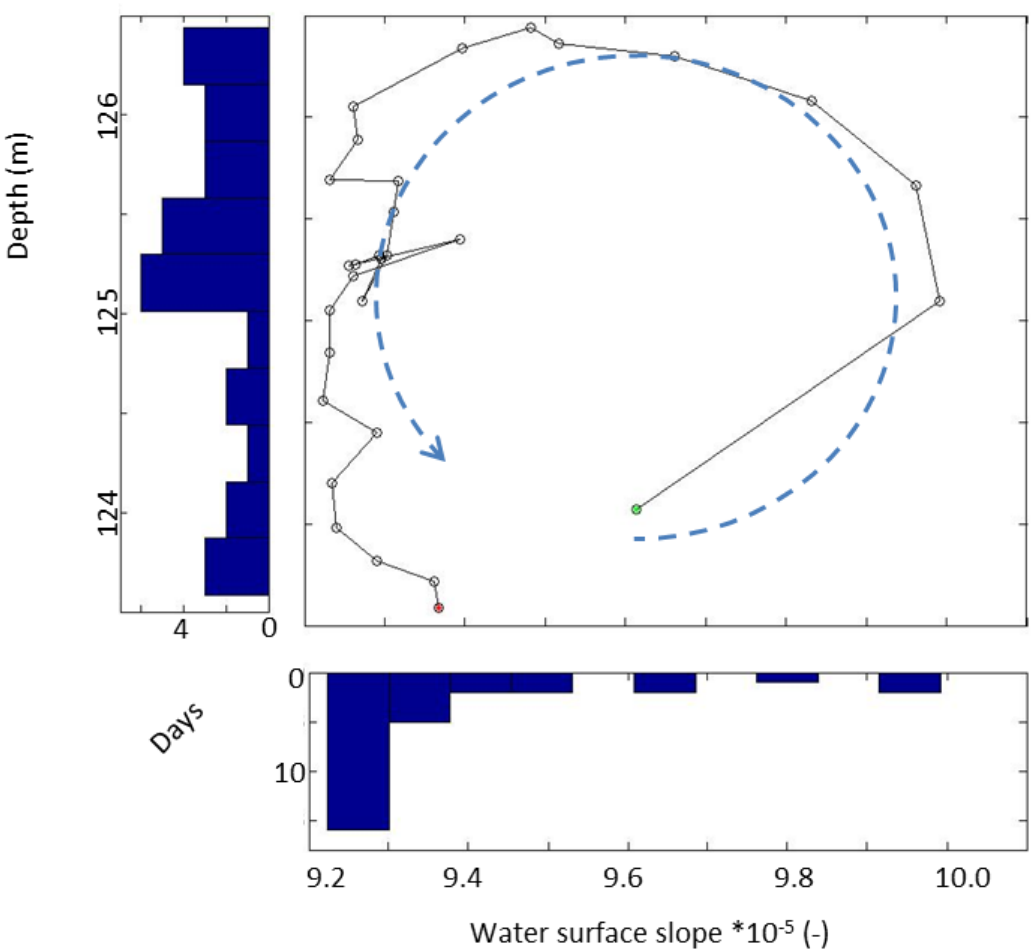

Figure 3. Water depth and water surface slope in the Mississippi River between the gauging stations at Saint Louis, MO and Chester, IL (data from USGS Water Information System). The distance between these stations is $114 \mathrm{~km}$, and the average elevation difference is $10.7 \mathrm{~m}$. The velocity of the flood wave was $171 \mathrm{~km} / \mathrm{day}$, and the flood lasted for approximately 30 days. The data show that the out-of-phase relation between depth and slope is significant for non-tidal rivers. The larger number of days during which the water depth is high and water-surface slope is decreasing (top left corner, waning flood stage) may bias observations of hydraulic conditions and corresponding dune behaviour in natural rivers. 


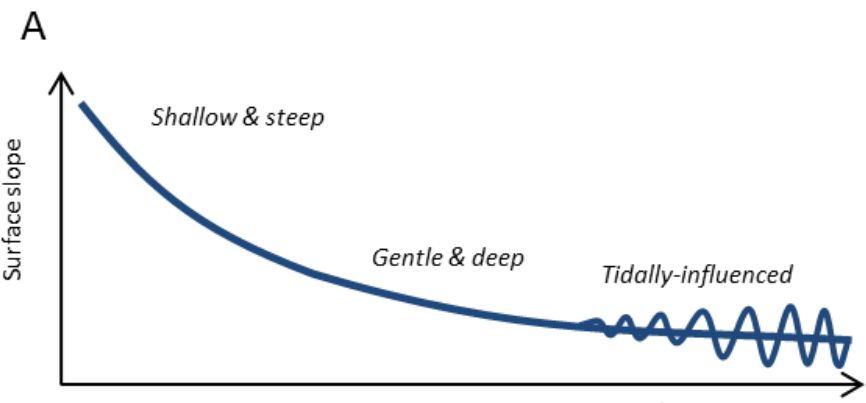

Downstream distance

B

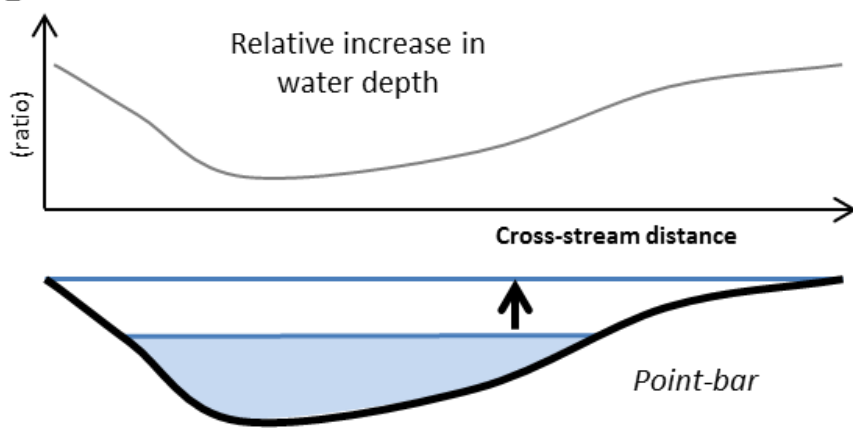

Figure 4. The magnitude of changes in flow depth and water-surface slope vary spatially: A) along a river within a catchment from shallow and steep upland streams, to deep and low-gradient lowland rivers to tidallyinfluenced rivers, and, B) locally across the channel from the thalweg to the bar tops. The relative change in water depth is very large on bar flanks and bar tops. 

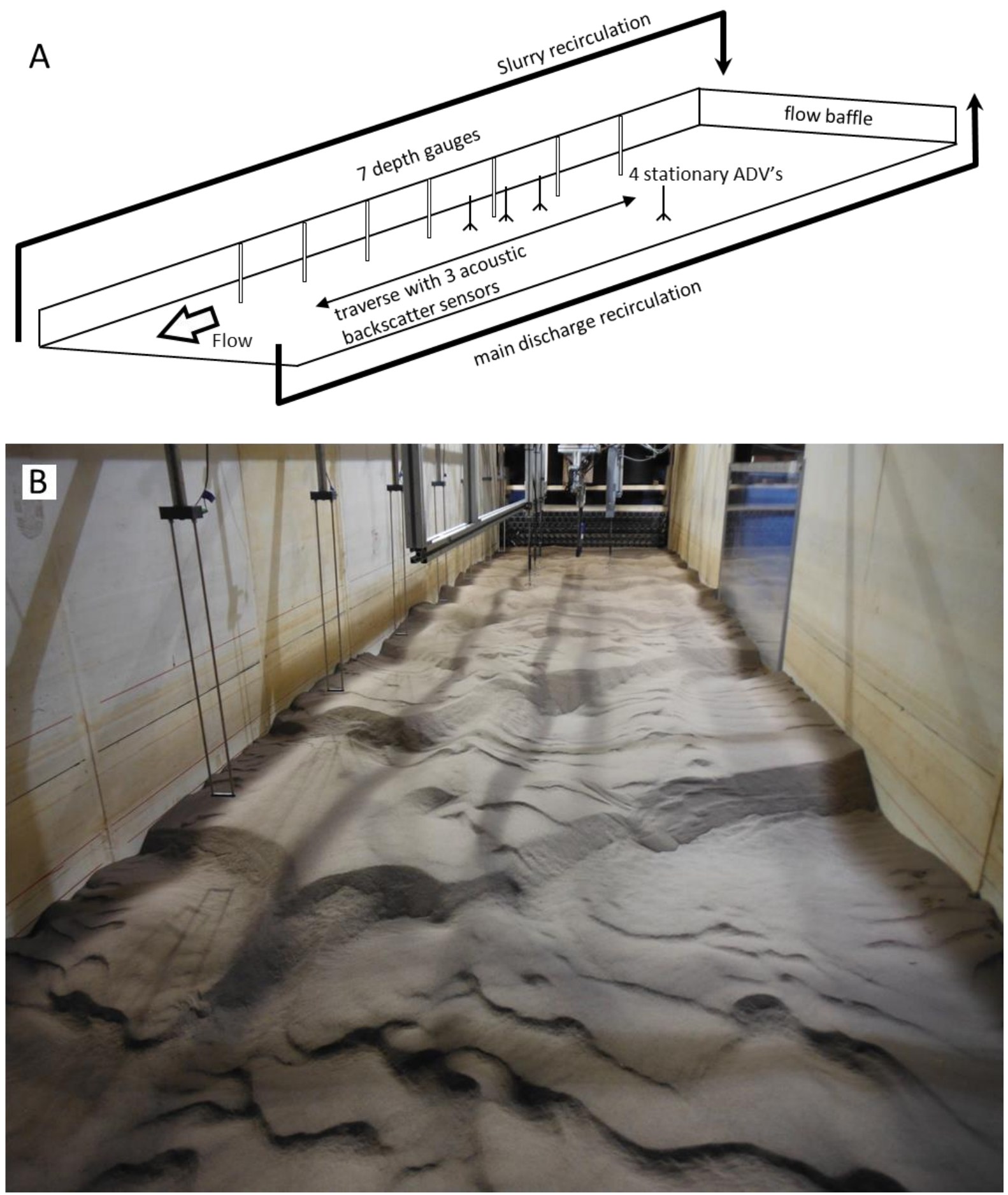

Figure 5. A) Diagram of the experimental set-up and B) photograph of the drained flume bed, 

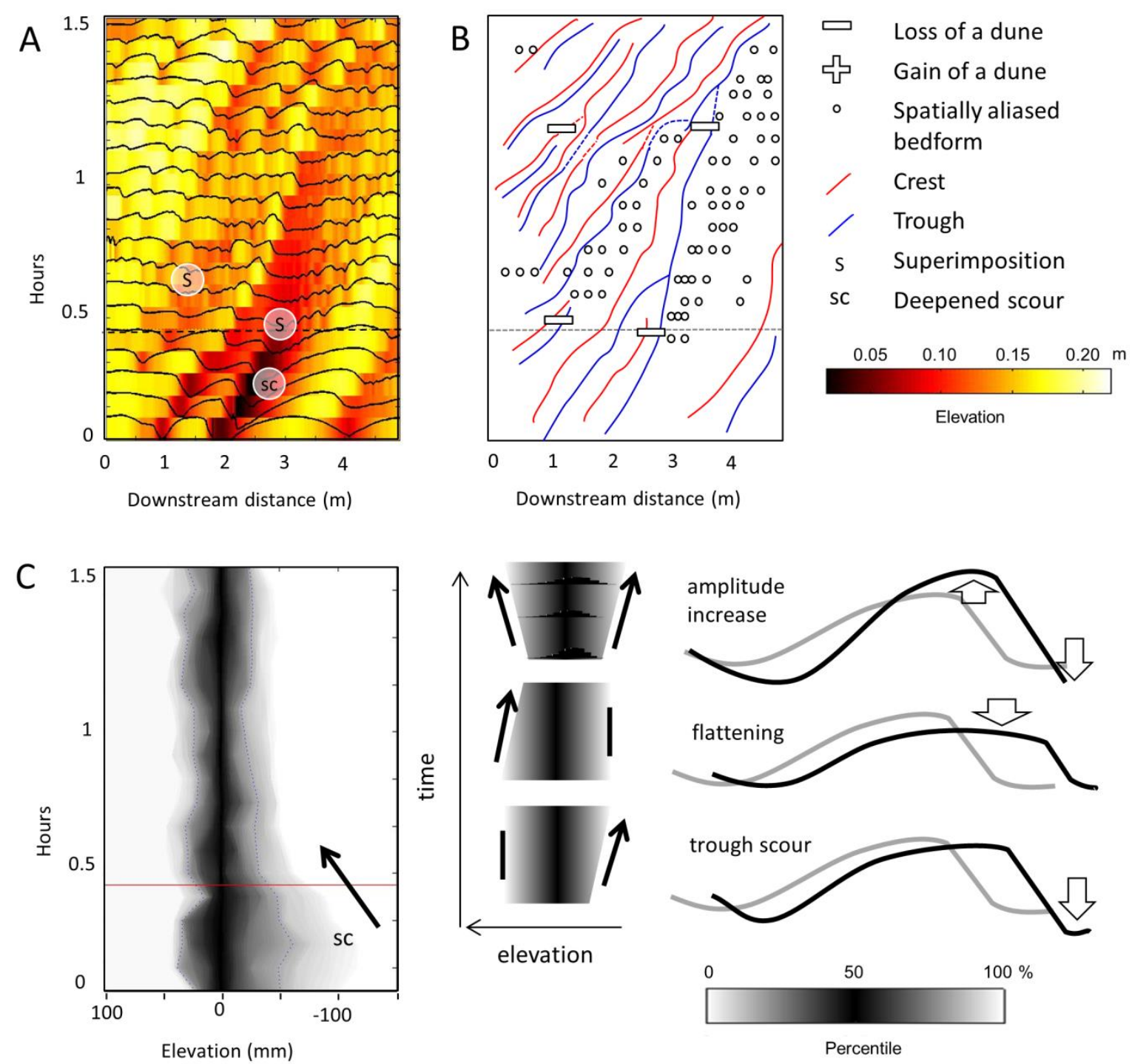

Percentile

Figure 6. A) Dune profiles over time (cf. Raudkivi and Witte, 1990) and for change in conditions (Table 2). The changes in flow are imposed at $0.5 \mathrm{~h}$. B) The kinematic interpretation associated with A. The example (Table 2) illustrates the presence of trains of superimposed bedforms following the loss of two dunes. The dune profiles and kinematic analyses of all 23 stage changes are given in Figures 9 and 11. C) Temporal development of the distribution of the bed elevation illustrates that changes in the elevation of troughs and crests are commonly out-of-phase. The red line indicates the time of the imposed change in flow. The analysis of bed elevations in all 23 stage changes is given in Figure 13. 
A Migration and deformation of a dune profile over time

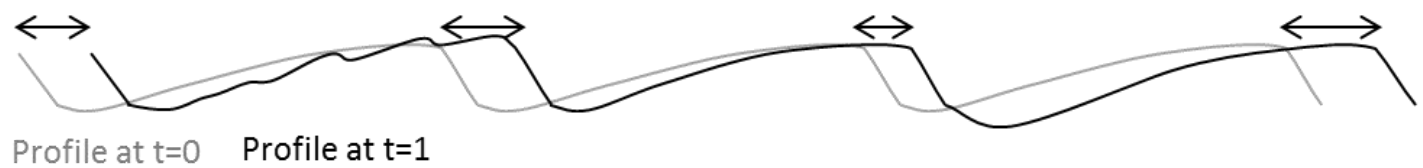

B Cross-correlated profiles (corrected for migration-lag)

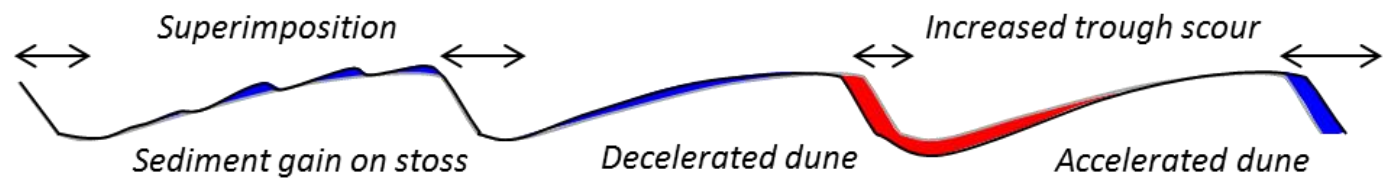

C

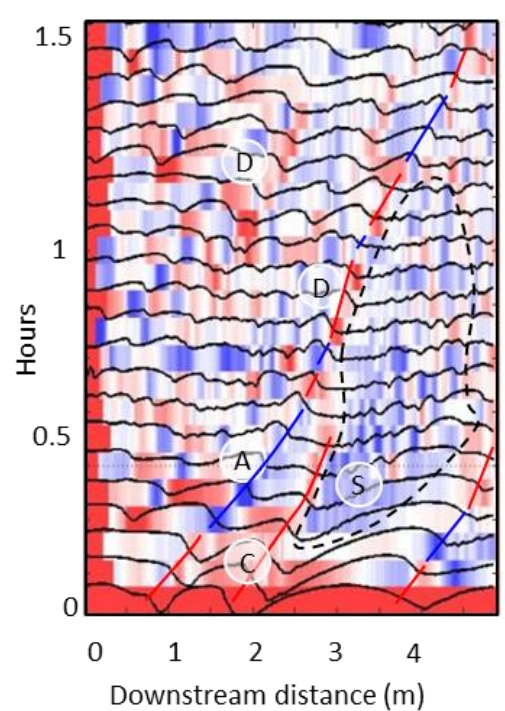

D

No change in shape

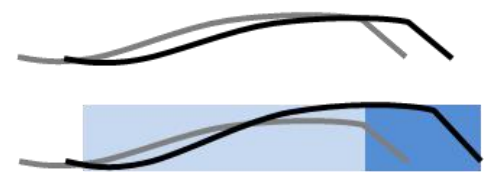

G - Growth

A - Acceleration

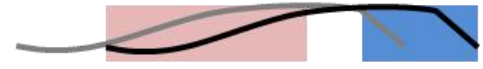

C - Decay

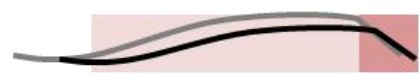

D - Deceleration

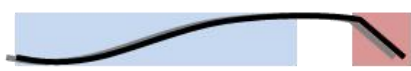

S - Superimposition

Figure 7. A-B) The residuals of a dune profile cross-correlation analysis (cf. McElroy and Mohrig, 2009) visualise local gain and loss of sediment within a mobile dune field. C-D) when plotted over time, different signatures indicate different processes (see also Fig. 2). Red and blue lines in (C) indicate the relative loss and gain of sediment from lee slopes respectively. The dashed black line in $C$ outlines a zone with a dominant gain of sediment. 


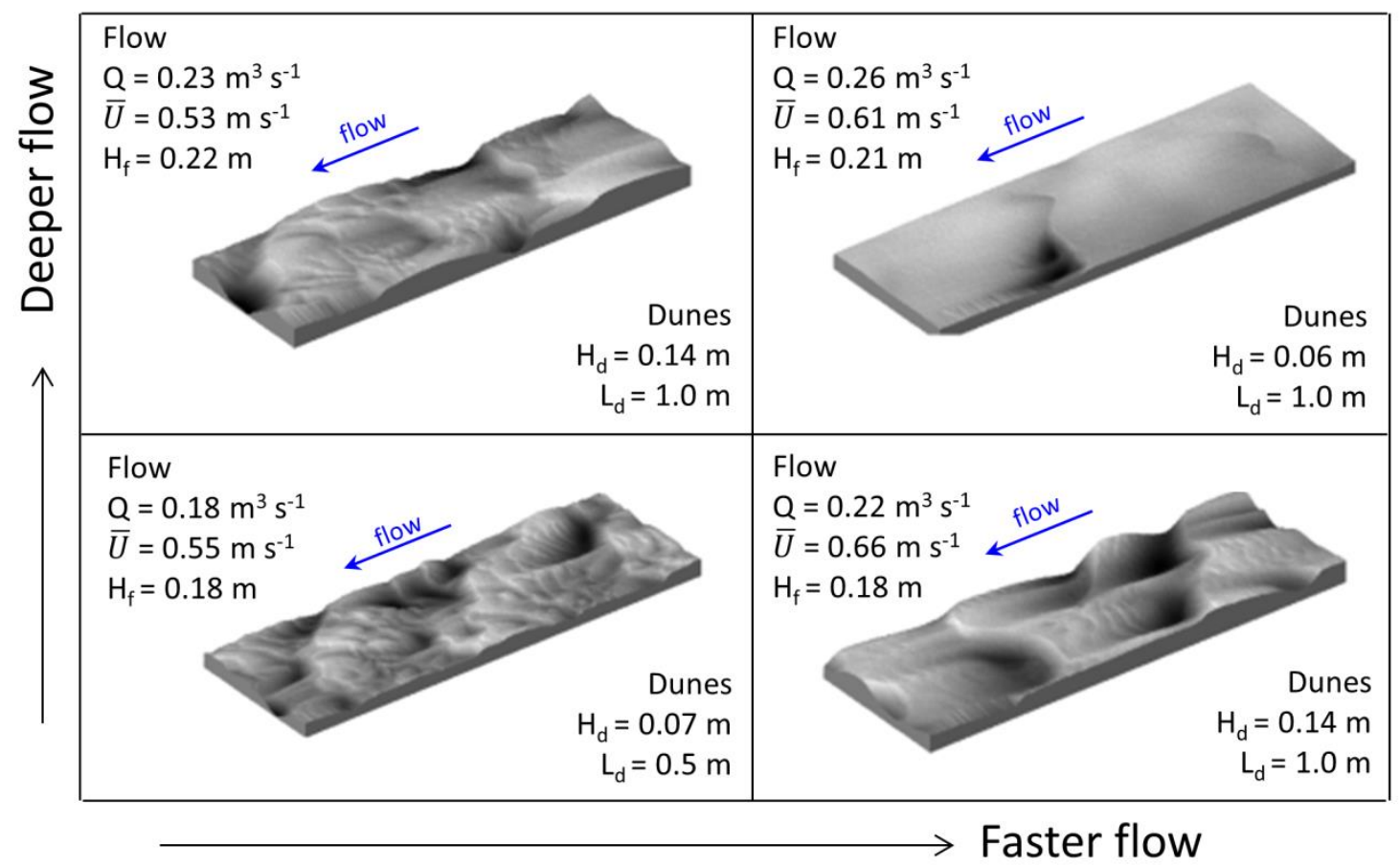

Figure 8. Scanned sections of four dune beds $3 \mathrm{~m}$ long and $1 \mathrm{~m}$ wide, associated with conditions 3 , 1392 11, 17, and 24 (see Table 1). Different dune morphology is observed for different conditions, which implies that dunes must adapt to imposed changes in flow velocity and depth. 

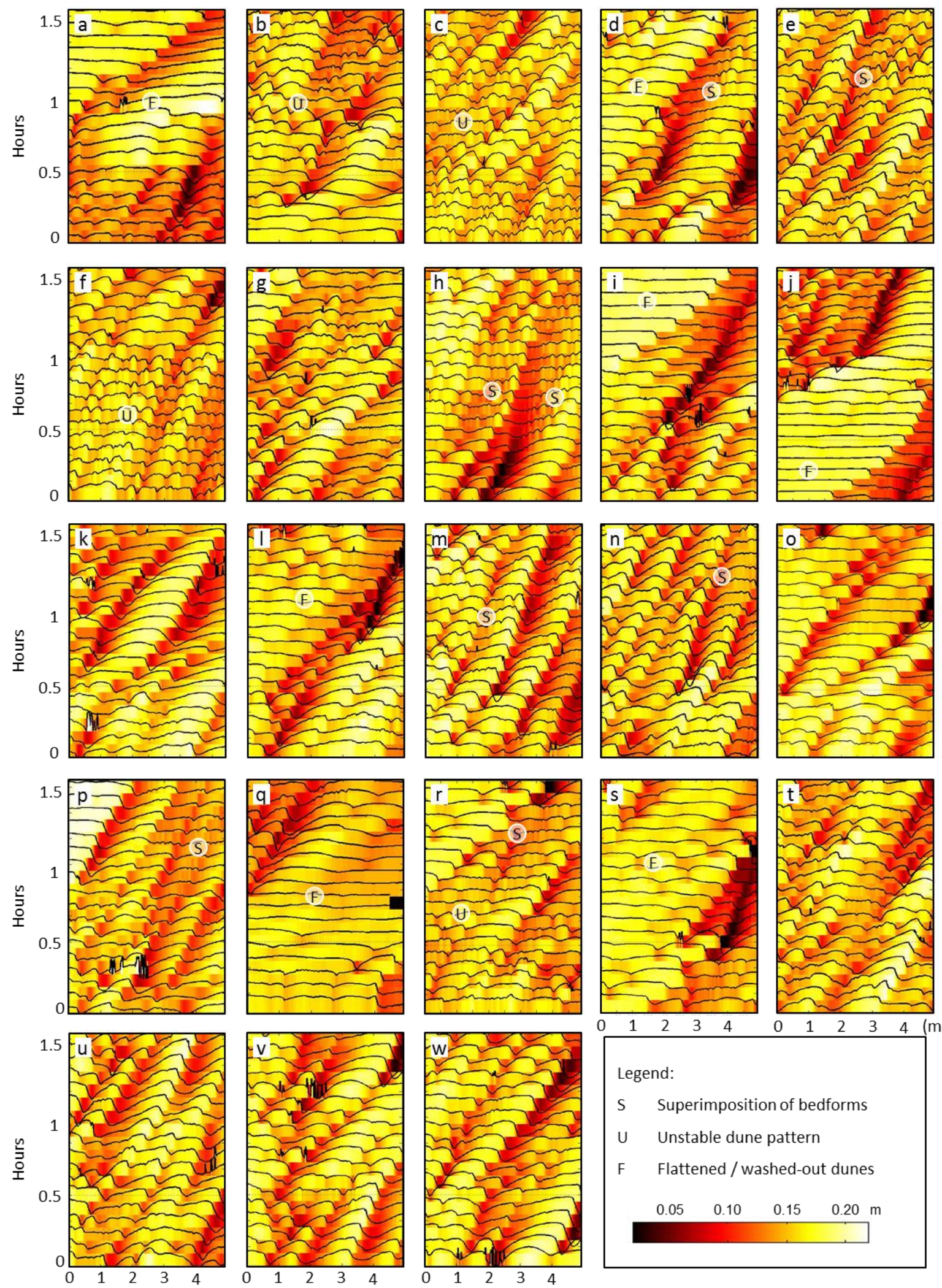

Downstream distance $(\mathrm{m})$

Figure 9. Consecutive bed elevation profiles plotted over time and coloured by bed elevation that illustrate the development of the dunes and superimposed bedforms. A-W correspond to the stepwise changes in flow detailed in Table 2. The profiles depict bed profiles 30 minutes prior to the change and 1 hour post-change conditions. 
A

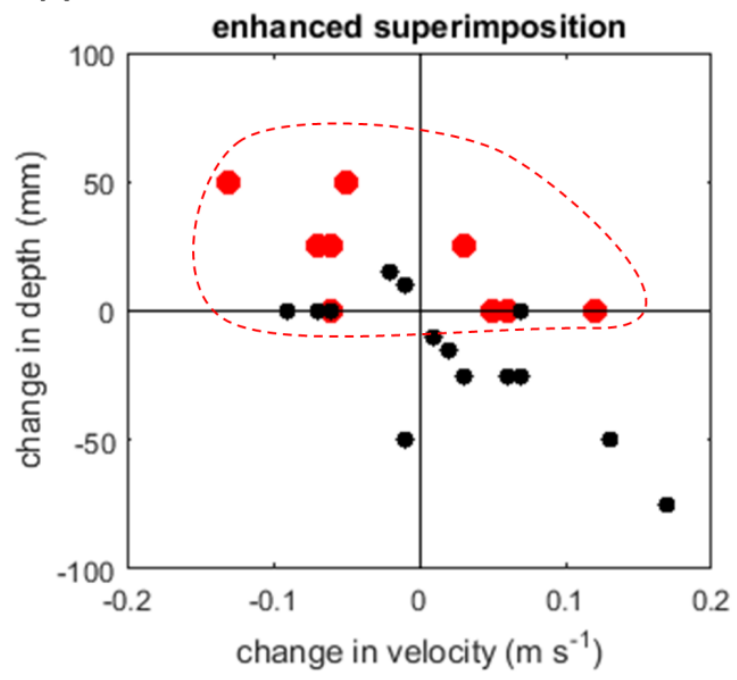

C

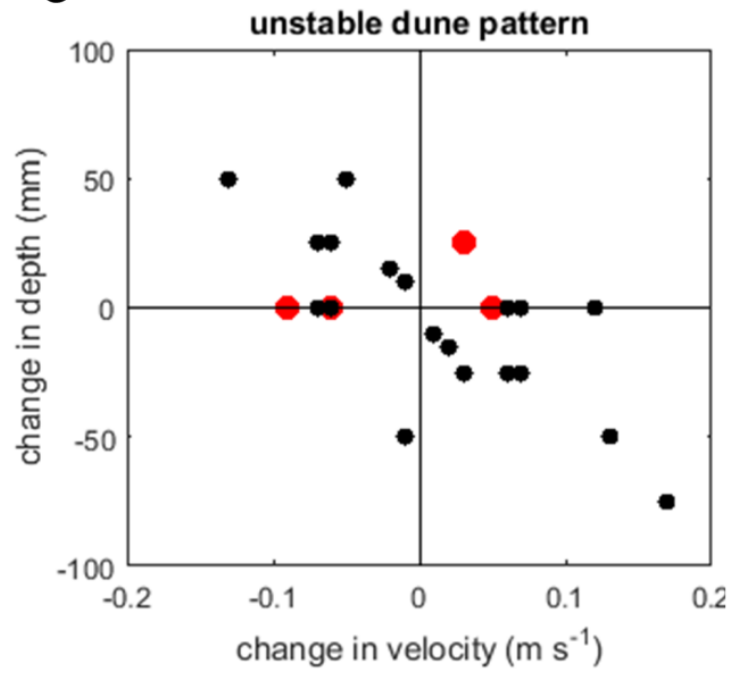

B

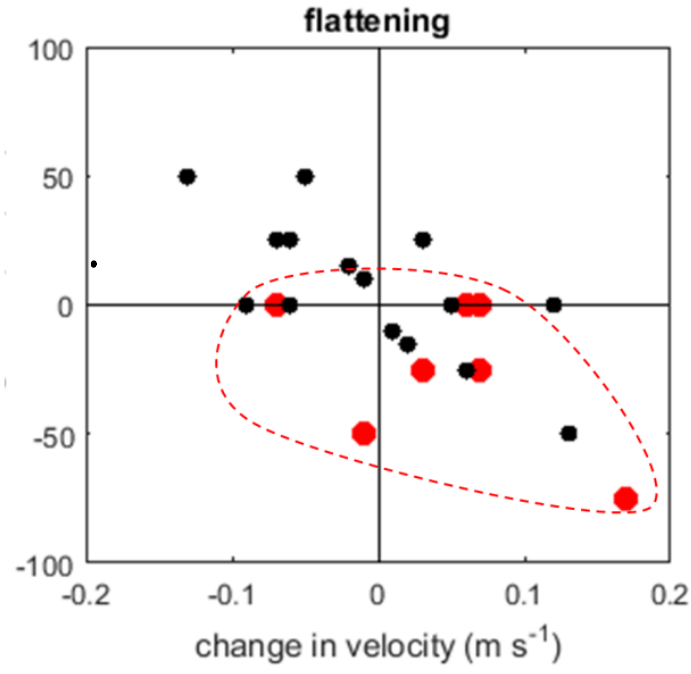

D

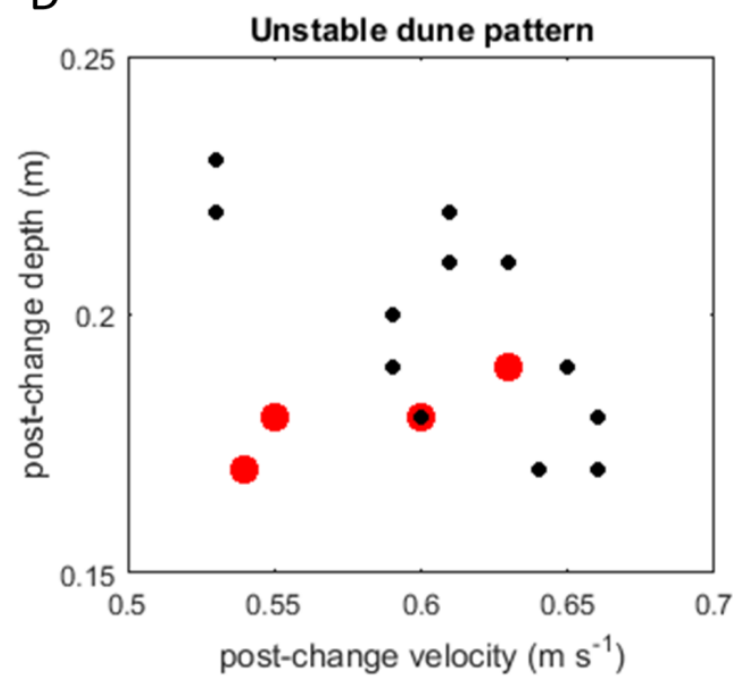

Figure 10. Scatterplots illustrating the preferential occurrence of processes among all experimental conditions: A) The development of trains of superimposed bedforms; B) the flattening of dunes; C) instability of the dune pattern plotted against the change in depth and velocity; D) instability of the dune pattern plotted against the post-change water depth and flow velocity (red = morphological response is observed, black = all data). The clustering of observations of superimposition and flattening within the plots indicates a dependency on the direction of changes in flow depth and velocity. Superimposition is more common when flow depth is increased, whereas flattening of the dune profile is most common when flow velocity is increased or flow depth is decreased. 

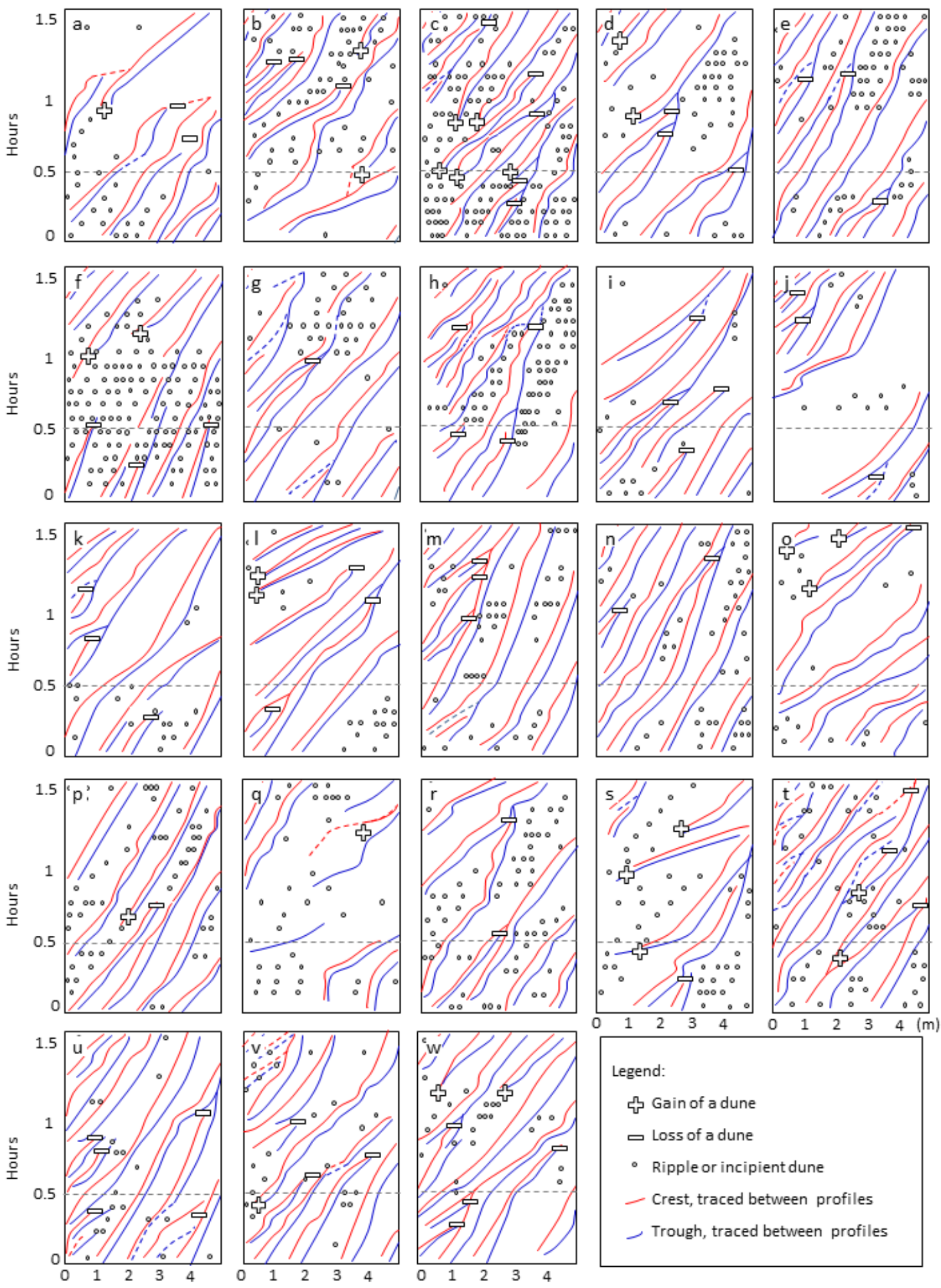

Downstream distance $(\mathrm{m})$

Figure 11. Kinematic interpretation of Figure 8: red and blue lines indicate crests and troughs of the dunes respectively, circles indicate bedform crests that could not reliably be traced between profiles, + and - symbols indicate gain and loss of dunes. a-w correspond to the step-wise changes in flow in Table 2. The profiles include 30 minutes prior to the change and 1-hour post-change conditions. 
A

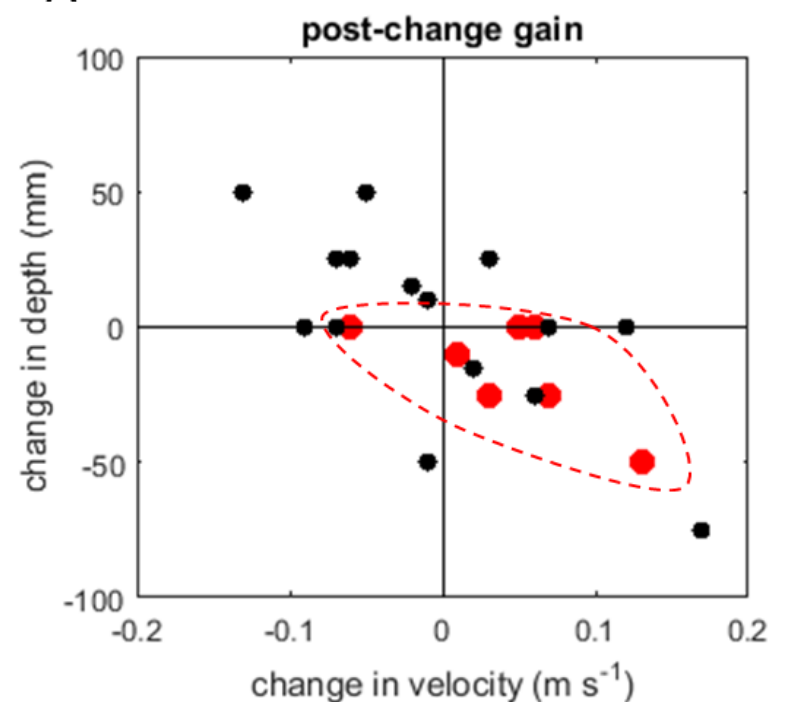

B

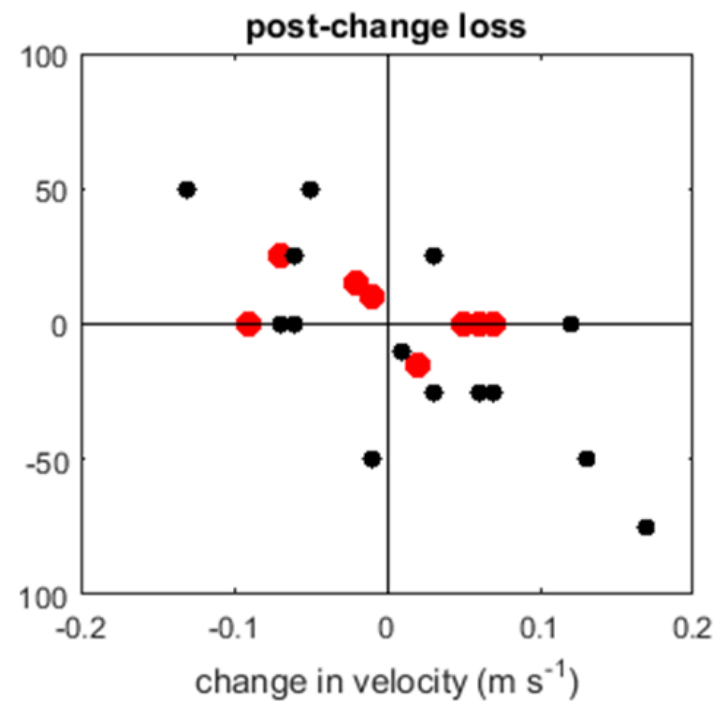

Figure 12. A) Addition of dunes to the dune profile, B) loss of dunes from the dune profile plotted against the water depth and flow velocity ( $r e d=$ morphological change is observed, black = all data). 

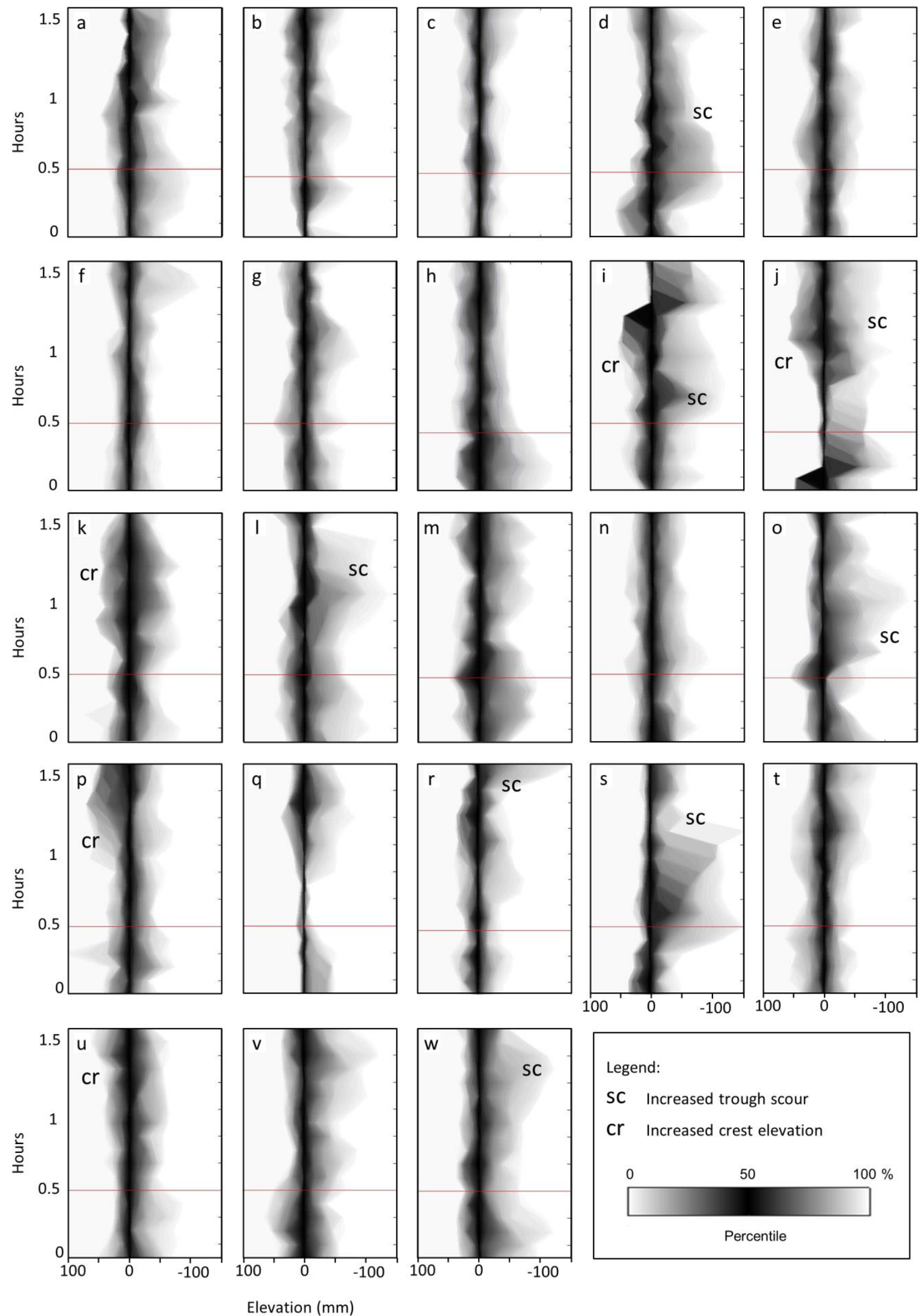

Figure 13. Distributions of the bed elevation in the $5 \mathrm{~m}$ long test section centred around the median. a-w correspond to the stepwise changes in flow detailed in Table 2. Each time-slice represents a bedelevation distribution, coloured from $0 \%$ (white), to the median (black), to $100 \%$ of the data. sc 
indicates enhanced scour, $\mathrm{cr}$ indicates an increase in the elevation of the crest. Note that the elevation distribution typically develops in an asymmetrical manner.

A

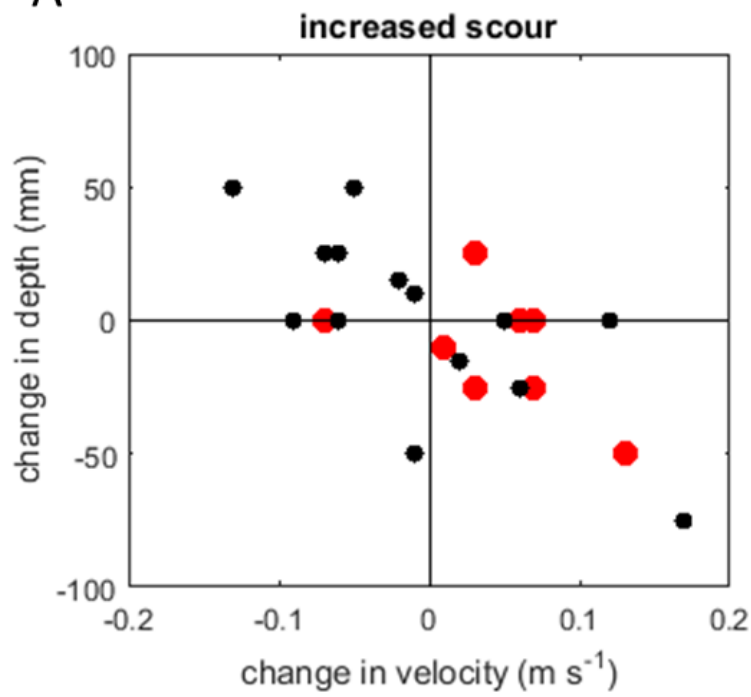

B

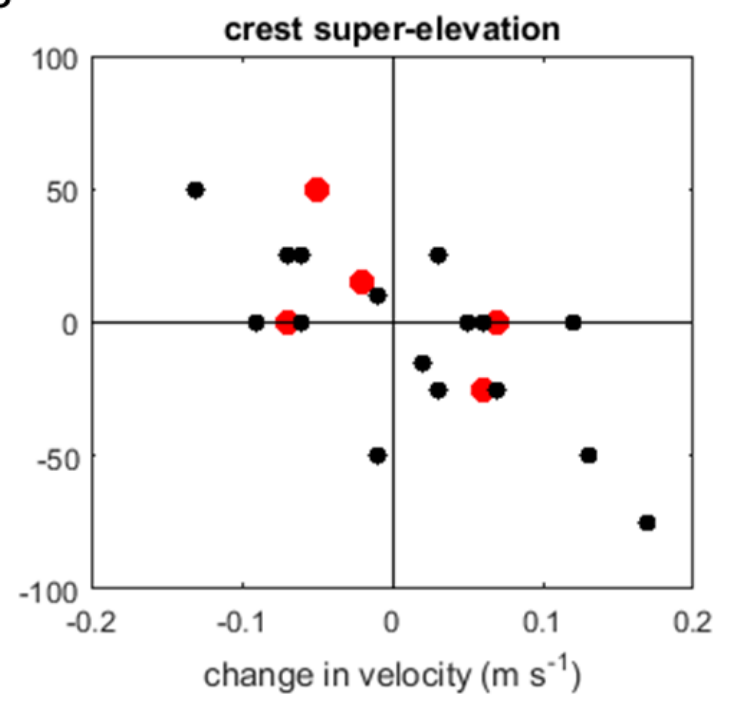

Figure 14. A) The increase of scour and B) super-elevation of dune crests above the remaining profiles as identified from the bed elevation distributions, and plotted as a function of water depth and flow velocity (red $=$ morphological change is observed, black $=$ all data). Note that increased scour is mostly observed under the higher velocities, and superelevation of the crest is mostly observed in the deeper flows. 

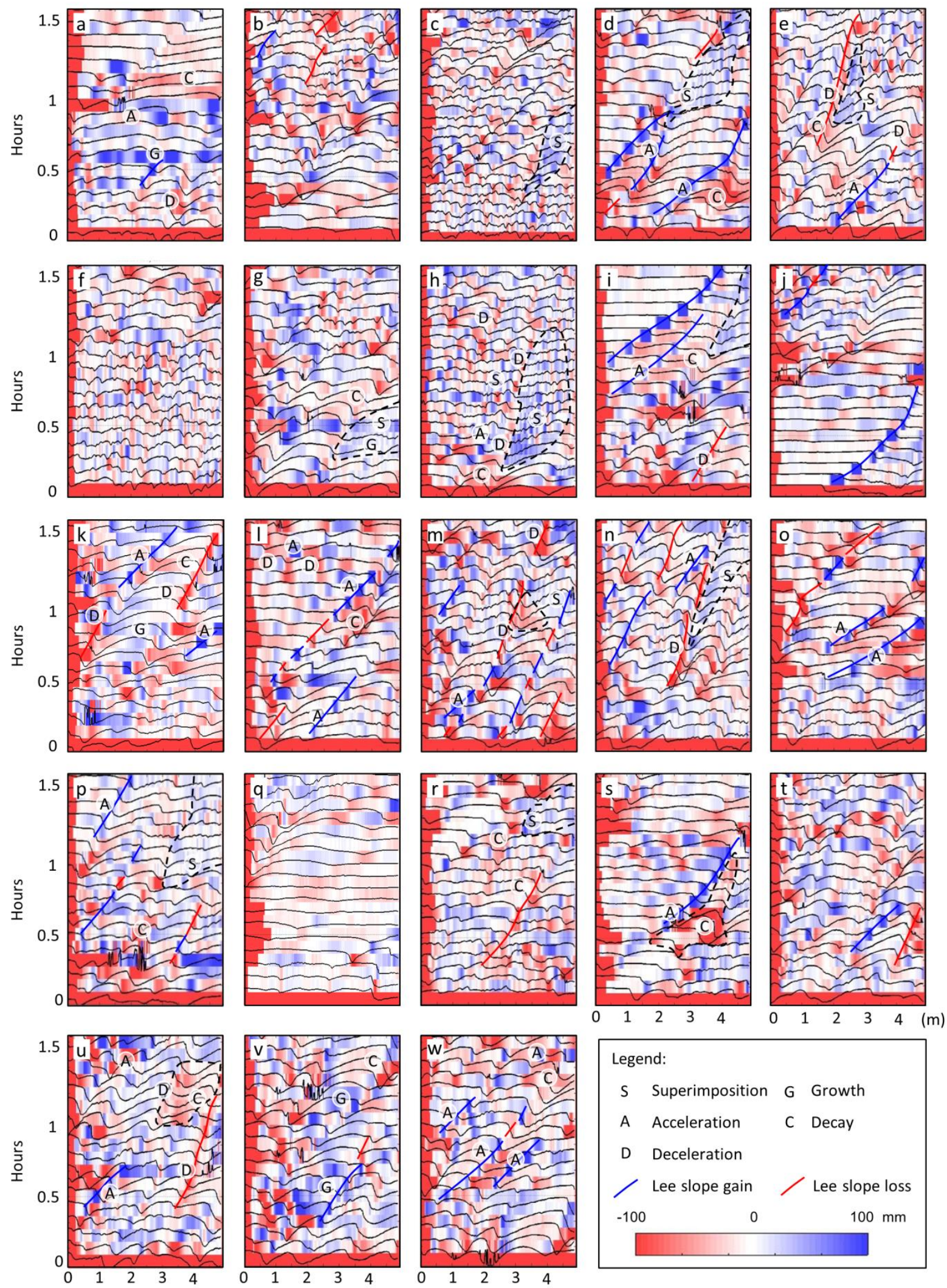

Downstream distance $(\mathrm{m})$

Figure 15. Consecutive profiles coloured by deformation (see also Fig. 7A-B). Note that zones of increased erosion and deposition relative to the mean profile shift persist over time: this indicates that some dunes systematically attract sediment whereas others systematically shed sediment. 
Trains of superimposed bedforms appear systematically on stoss slopes that attract sediment (decreased migration of the stoss relative to the mean dune migration).

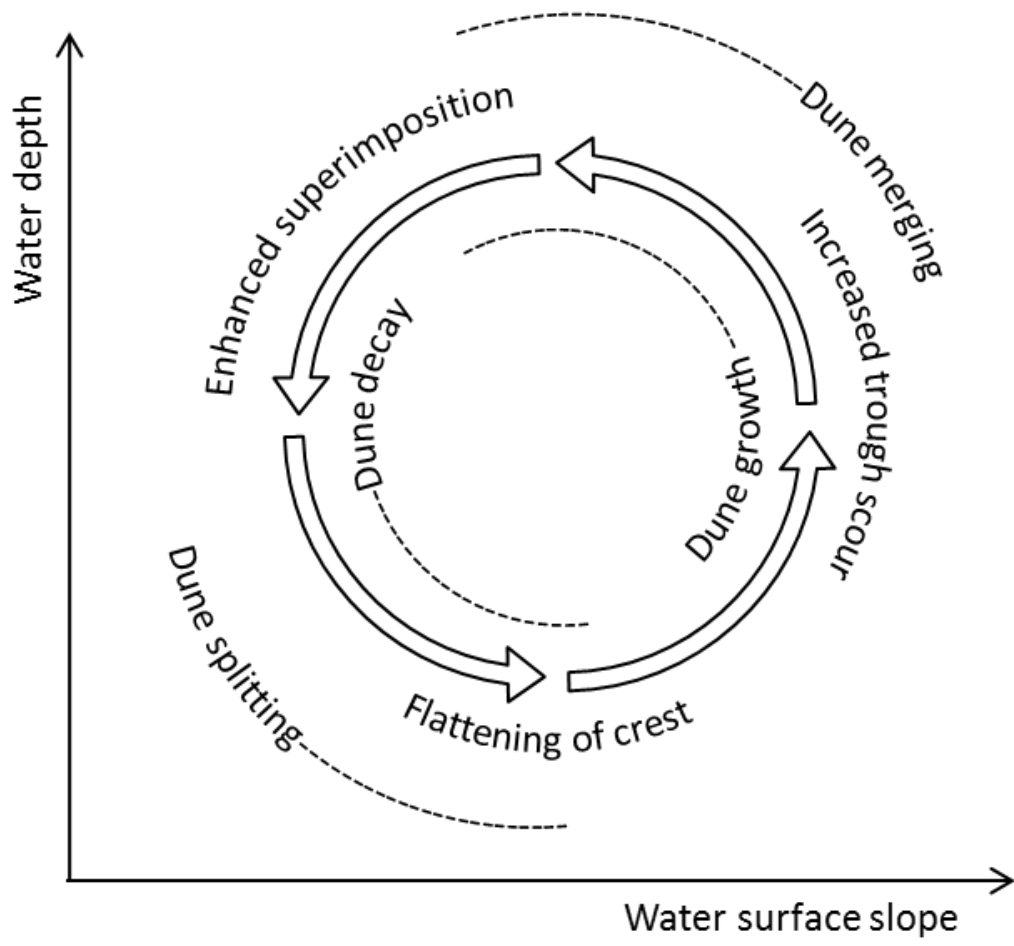

Figure 16. Conceptual model of expected changes in dune adaptation processes during a flood wave for the thalweg of a medium-sized river, based on the present experiments with shallow, unidirectional flows (depth 0.17-0.25 m). The nature of this conceptual model will require adaptation for different geomorphological settings, such as locations with different grain sizes, strong secondary currents, deep flows, or multidirectional flows. 
Table 1. Overview of the 24 investigated flow conditions. $Q$ is discharge, $\mathrm{H}_{\mathrm{f}}$ is flow depth, $\bar{U}$ is depthaverage velocity, $\mathrm{Fr}$ is Froude number, $H_{d}$ is average dune height, $L_{d}$ is average dune length.

\begin{tabular}{|r|c|c|c|c|c|c|}
\hline & $\mathbf{Q}\left(\mathbf{m}^{\mathbf{3}} \mathbf{s}^{-1}\right)$ & $\mathbf{H}_{\mathbf{f}}(\mathbf{m})$ & $\bar{U}\left(\mathbf{m ~ s}^{-1}\right)$ & $\mathbf{F r}$ & $\mathbf{H}_{\mathbf{d}}(\mathbf{m})$ & $\mathbf{L}_{d}(\mathbf{m})$ \\
\hline $\mathbf{1}$ & 0.22 & 0.25 & 0.46 & 0.3 & 0.11 & 1.0 \\
\hline $\mathbf{2}$ & 0.212 & 0.17 & 0.64 & 0.49 & 0.09 & 1.3 \\
\hline $\mathbf{3}$ & 0.182 & 0.18 & 0.55 & 0.42 & 0.07 & 0.5 \\
\hline $\mathbf{4}$ & 0.2 & 0.18 & 0.6 & 0.46 & 0.16 & 1.3 \\
\hline $\mathbf{5}$ & 0.22 & 0.18 & 0.66 & 0.5 & 0.12 & 1.0 \\
\hline $\mathbf{6}$ & 0.2 & 0.18 & 0.6 & 0.46 & 0.08 & 0.7 \\
\hline $\mathbf{7}$ & 0.18 & 0.17 & 0.54 & 0.41 & 0.14 & 1.1 \\
\hline $\mathbf{8}$ & 0.22 & 0.18 & 0.66 & 0.5 & 0.18 & 1.2 \\
\hline $\mathbf{9}$ & 0.228 & 0.23 & 0.53 & 0.36 & 0.14 & 1.0 \\
\hline $\mathbf{1 0}$ & 0.26 & 0.22 & 0.61 & 0.41 & 0.19 & 1.6 \\
\hline $\mathbf{1 1}$ & 0.228 & 0.22 & 0.53 & 0.36 & 0.14 & 1.0 \\
\hline $\mathbf{1 2}$ & 0.224 & 0.19 & 0.59 & 0.42 & 0.14 & 1.3 \\
\hline $\mathbf{1 3}$ & 0.22 & 0.18 & 0.66 & 0.5 & 0.19 & 1.1 \\
\hline $\mathbf{1 4}$ & 0.224 & 0.20 & 0.59 & 0.42 & 0.12 & 1.1 \\
\hline $\mathbf{1 5}$ & 0.228 & 0.22 & 0.53 & 0.36 & 0.14 & 1.1 \\
\hline $\mathbf{1 6}$ & 0.22 & 0.17 & 0.66 & 0.5 & 0.18 & 0.9 \\
\hline $\mathbf{1 7}$ & 0.26 & 0.21 & 0.61 & 0.41 & 0.06 & 1.0 \\
\hline $\mathbf{1 8}$ & 0.2 & 0.18 & 0.6 & 0.46 & 0.08 & 0.7 \\
\hline $\mathbf{1 9}$ & 0.24 & 0.19 & 0.63 & 0.45 & 0.11 & 1.2 \\
\hline $\mathbf{2 0}$ & 0.22 & 0.18 & 0.66 & 0.5 & 0.11 & 1.0 \\
\hline $\mathbf{2 1}$ & 0.23 & 0.19 & 0.65 & 0.49 & 0.14 & 1.1 \\
\hline $\mathbf{2 2}$ & 0.24 & 0.21 & 0.63 & 0.45 & 0.17 & 1.1 \\
\hline $\mathbf{2 3}$ & 0.23 & 0.19 & 0.65 & 0.49 & 0.17 & 0.9 \\
\hline $\mathbf{2 4}$ & 0.22 & 0.18 & 0.66 & 0.5 & 0.14 & 1.0 \\
\hline & & & & & & \\
\hline
\end{tabular}


Table 2. Overview of the 23 step changes and the observed post-change morphodynamic responses

\begin{tabular}{|c|c|c|c|c|c|c|c|c|c|c|c|c|c|c|c|c|c|}
\hline 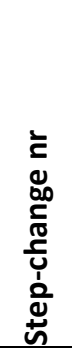 & 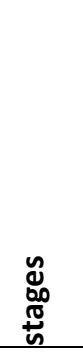 & 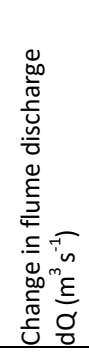 & 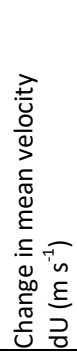 & 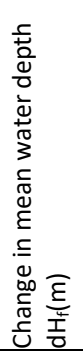 & 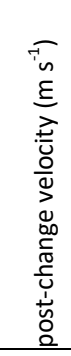 & 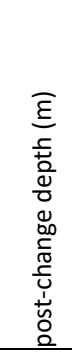 & 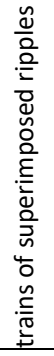 & 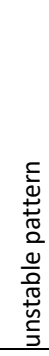 & $\begin{array}{l}\stackrel{00}{.} \\
\frac{.}{ \pm} \\
\underset{ \pm}{ \pm} \\
\frac{\pi}{4} \\
\end{array}$ & 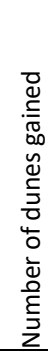 & 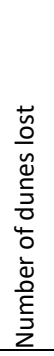 & 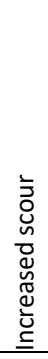 & 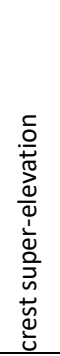 & 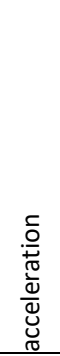 & 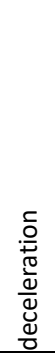 & 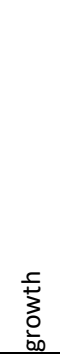 & $\begin{array}{l}\text { đ্ } \\
\mathbb{d}\end{array}$ \\
\hline $\mathrm{a}$ & $1-2$ & -0.008 & 0.17 & -0.75 & 0.64 & 0.17 & & & $y$ & 1 & 2 & & & $y$ & & $y$ & $y$ \\
\hline $\mathrm{b}$ & $2-3$ & -0.03 & -0.09 & 0 & 0.55 & 0.18 & & $y$ & & 1 & 3 & & & & & & \\
\hline c & $3-4$ & 0.018 & 0.05 & 0 & 0.6 & 0.18 & $y$ & $y$ & & 2 & 3 & & & & & & \\
\hline d & $4-5$ & 0.02 & 0.06 & 0 & 0.66 & 0.18 & $y$ & & $y$ & 2 & 3 & $\mathrm{Y}$ & & $y$ & & & \\
\hline $\mathrm{e}$ & $5-6$ & -0.02 & -0.06 & 0 & 0.6 & 0.18 & $y$ & & & 2 & 2 & & & & $y$ & & $y$ \\
\hline $\mathrm{f}$ & $6-7$ & -0.02 & -0.06 & 0 & 0.54 & 0.17 & & $y$ & & 2 & 2 & & & & & & \\
\hline $\mathrm{g}$ & $7-8$ & 0.04 & 0.12 & 0 & 0.66 & 0.18 & $y$ & & & 0 & 1 & & & & & $y$ & $y$ \\
\hline $\mathrm{h}$ & 8-9 & 0.008 & -0.13 & 0.50 & 0.53 & 0.23 & $y$ & & & 0 & 2 & & & $y$ & $y$ & & \\
\hline $\mathrm{i}$ & $9-10$ & 0.032 & 0.07 & 0 & 0.61 & 0.22 & & & $y$ & 0 & 3 & $\mathrm{Y}$ & $Y$ & $y$ & & & $y$ \\
\hline $\mathrm{j}$ & $10-11$ & -0.032 & -0.07 & 0 & 0.53 & 0.22 & & & $y$ & 0 & 2 & $\mathrm{Y}$ & $Y$ & & & & \\
\hline $\mathrm{k}$ & $11-12$ & -0.004 & 0.06 & -0.25 & 0.59 & 0.19 & & & & 0 & 2 & & $Y$ & $y$ & $y$ & $y$ & $y$ \\
\hline I & $12-13$ & -0.004 & 0.07 & -0.25 & 0.66 & 0.18 & & & $y$ & 2 & 2 & $\mathrm{Y}$ & & $y$ & $y$ & & $y$ \\
\hline $\mathrm{m}$ & 13-14 & 0.004 & -0.07 & 0.25 & 0.59 & 0.20 & $y$ & & & 0 & 3 & & & & $y$ & & \\
\hline $\mathrm{n}$ & $14-15$ & 0.004 & -0.06 & 0.25 & 0.53 & 0.22 & $y$ & & & 0 & 2 & & & $y$ & $y$ & & \\
\hline 0 & $15-16$ & -0.008 & 0.13 & -0.50 & 0.66 & 0.17 & & & & 3 & 1 & Y & $Y$ & $y$ & & & \\
\hline$p$ & $16-17$ & 0.04 & -0.05 & 0.50 & 0.61 & 0.21 & $y$ & & & 1 & 1 & & $Y$ & $y$ & & & $y$ \\
\hline$q$ & $17-18$ & -0.06 & -0.01 & -0.50 & 0.6 & 0.18 & & & $y$ & 1 & 0 & & $Y$ & & & & \\
\hline$r$ & $18-19$ & 0.04 & 0.03 & 0.25 & 0.63 & 0.19 & $y$ & $y$ & & 0 & 2 & $\mathrm{Y}$ & & & & & \\
\hline $\mathrm{s}$ & $19-20$ & -0.02 & 0.03 & -0.25 & 0.66 & 0.18 & & & $y$ & 2 & 0 & $Y$ & & & & & $y$ \\
\hline $\mathrm{t}$ & $20-21$ & 0.01 & -0.01 & 0.10 & 0.65 & 0.19 & & & & 1 & 3 & & & $y$ & & & $y$ \\
\hline u & 21-22 & 0.01 & -0.02 & 0.15 & 0.63 & 0.21 & & & & 0 & 3 & & $Y$ & $y$ & $y$ & & $y$ \\
\hline$v$ & $22-23$ & -0.01 & 0.02 & -0.15 & 0.65 & 0.19 & & & & 0 & 3 & & & & & $y$ & $y$ \\
\hline w & 23-24 & -0.01 & 0.01 & -0.10 & 0.66 & 0.18 & & & & 2 & 2 & & & $y$ & & & $y$ \\
\hline
\end{tabular}

